PPPL-1887

UC20 F

\title{
LOW-ENERGY X-RAY EMISSION FROM \\ MAGNETIC-FUSION PLASMAS
}

BY

K.W. Hill, M. Bitter, D. Eames, S. von Goeler,

M. Goldman, N.R. Sauthoff, and E. Silver

Apri1 1982

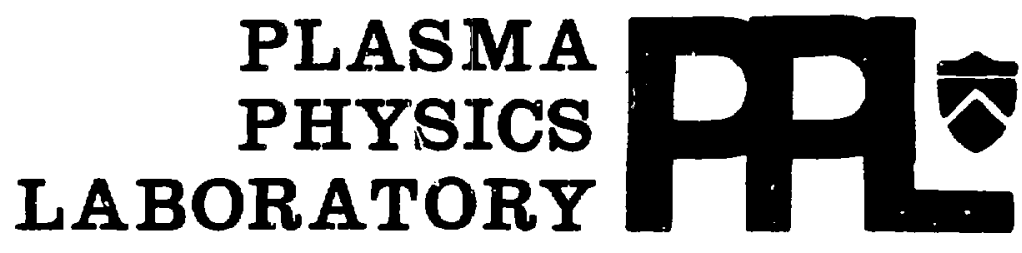

\section{PRINCETON UNIVERSITY}

PRINCETON, NEW JERSEY

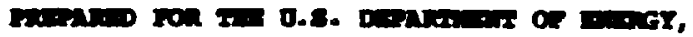

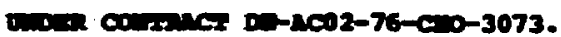


Low Energy X-Ray Emission from Magnetic Fuston Plamas

X.W. Hill, M. Bitter, D. Eanes, S. von Goeler,

M. Golaman, N.K. Sauthozf, and E. SIlver

PPPL,--1887

DE\$? 009817

Princeton University, Plasma Physics Laboratc:y

Princeton, New Jersey 08544

ABSTRACT

Complex, transient, spatially Inhomogeneous tokamak plasmas require careful diagnosis. As the reactor regine 1 s approached, ooft $x$ : $1 y$ s become more important as a versatile diagnostic tool and an energy-loss "echanism. Continuum emission provides a measure of electron teaperature id ilght impurity content. Impurity 11nes serve as a probe for 10 and electron temperature, impurity behavior, and radiative cooling. The entire spectrum yields vital information on instabilities and disruptions. The lmportance of Impuritled is illustrated by the extensive efforts toward understanding impurity production, effects, and control, Minute heavy impurity concentrations can prevent reactor ignition. $\$ 1(L 1)$ - detector arrays glve a broad overview of continum and line $x$-ray eniesion $(.3-50$ kev) with moderate energy $(200 \mathrm{ev})$ and time $(50 \mathrm{~ms})$ resolution. Hragg crystal and grating spectrometers provide detalled information on impurity ifnes with moderate to excellent $\langle E / \Delta E=100-23,000)$ resolving pover and $1-50$ ms time resolution. Imaging detector arrays messure rapid ( 10 ps) Eluctuations due to MHD instabilities and probe impurity behavior and radiative cooling. Future tokamaks require more diagnostic channels to avold bpatial scanning, hlgher throughput for fast, single-shot diagnosis, increased spectral 
Information per sample period via rast scanning or use of multi-element detectors with dispersive elements, and radiation shielding and hardening of detectors.

This report vas presented as an invited review paper at the AIP Conference on Low Energy X-kay Dlagnostics, Monterey, Cal1fornia, June 8-10, 1981. 


\section{INTRODUCTION}

Controlled Fusion offers the hope of an essentially unlimited supply of energy with fuel avaliable to all nations [1]. Dlagnosticg instrumentation plays an important role in controlled fusion research [2-5]. It serves as the "eyes" and "ears" of the experimental physicist, enabling him to monitor his progress in the quest for attaining optinal conditions for fusion. The transient plasma of most of today's fusion-research devices and the large number and complexity of 1mportant interacting physical processes demand measurement of several physical parameters with good temporal and spatial resolution. As p.lasma temperatures become higher, the electromagnetic spectrum emitted by the plasma shifts toward shorter wavelengths, and $x$ rays become more Important both as a source of radiative power loss and as a means of making diagnogtic neasurements [6]. Several types of Instruments have been developed over the yearg to probe fusion plagmas by measuring varlous properties of the $x$-ray emission [3-30]. A necessary part of these developments has been the contribution of expertise by scientists in many areas, such as solid stats, nuclear, and atomic physics, astrophysics, crystallography, electron1cs, etc. These ingtruments permit measurement of a varlety of important plisma parameters. These include electron $[8,37,45 j$ and ton [22] temperatures, clensity [31], plasma equilibriun and stability [23,24], plasma position, and plasma rotation [6]. Other parameters inferred from $x$ rays relate to Impurities and include radiative energy $1069[10,32-35]$, concentration $[6,8,10]$ and motion $[36]$, charge-state distribution $[21,37]$, wavelengths of emission lines [38-42], and atomic physics parameters such as cross aections for excitation, forization, and recombination $[43,44,46,47]$. 
This paper is a review of X-ray diagnostic techniques and apparatus, used in magnetic confinement fusion experiments, involving measurement of $\mathrm{x}$-ray enission in both the low energy or ultrasoft $\mathrm{X}$-ray (USX) region ( 0.1 to $1 \mathrm{keV}$ ) and the soft $\mathrm{x}$-ray region $(\mathrm{SX})(1-10 \mathrm{kev})$. This extended range is addressed because some instruments operate in both regions and others are applicable to both ranges but have historically operated in the SX region due to the greater couplexity required for USx operaticn. The low energy or USX range, however, is particularly important because the emission in this region is often a significant fraction of the energy loss in tokamaks [10,32-35]. Although various types of magnetic confinement devices exist and some are addressed in the paper, the bulk of the work reported involves tokamaks.

This paper focuses on describing magnetic fuston energy (MFE) $x$-ray diagnostics to sclentists who may not be involved in or have intimate knowledge of MFE. Review information on basic principles of MFE are presented without going into detall. The tokamak is used as an example although some $\mathrm{x}-$ ray diagnost.1c work from other MFE devices is presented. An effort is made to illustrate what the diagnostic needs and problem areas are so that regearchers in uther flelds can understand how they might contribute to the diagnostic effort. In section II we review the basic principles of the tokamak. Section III emphasizes the importance of impurities. This importance ls supported by (a) the extensive work done toward studying impurities, their effects, and their cortrol, and (b) a sumnary of some specific impurity effects. In section IV the mechanions for $x$-ray production in plasmas and properties of this emission are reviewed. Section $\mathrm{v}$ describes the major $\mathrm{x}$-ray diagnostic instruments used on tokamaks. The purpose, principle of operation, and characteristics of each instrument are summarized. Examples of data are presented and discussed briefly. Section $v i$ describes some problems with 
pregent X-ray diagnostics, gome improvements planned for the Tokamak Fusion Test Reactor (TFTR) at Princeton Plasma Physics Laboratory (PPPL), and further development that would benefit the fuston program.

\section{THE TORAMAR}

At Princeton two tokamaks, the Princeton Large Torug (PLT) and Polotdal Divertor Experiment (PDX) are operating presently. A third larger machine, the Tokamak Fusion Test Reactor (TFYR) [56], w11l begin operation in 1982. The major goal of TFTR is to achleve "breakeven" (fuslon power out = heating power $2 a$ ) in deuterium-beam-heated tritiun plasma (DT operation). Several other tokamaks are in operation at other laboratories in the United statea and in ather countrieg. These Include the Alcator tokanaks at MIT, ISX-B (Impurity Studleg Experiment) at oak Ridge, Doublet III at General Atomic, DITE at Culham, U.K., TFR at Fontenay aux Roses, France, and others in Italy, Germany, Japan, the U.S.S.R., etc.

The tokamak has been revlewed in several papers $[1,48-55]$. A brief description follows. The basic componentg are shown schematically in Fig. 1. A hydrogen-1sotope plasma characterized by major radius $R$ ( 130 cm for PLT, $265 \mathrm{~cm}$ for TFTR) and minor radiug $\mathrm{r}=\mathrm{a}(40 \mathrm{~cm}$ for PLT, 85 cm for TFTR) $1 \mathrm{~s}$ created and heated in a toxoldal vacum vessel. A strong, static magnetic field $B_{T}(1-10 \mathrm{~T}$, depending on the type of tokamak and the regime of operation being studied) is superposed throughout the vacuum vessel by external toroidal fleld (TF) colls. The basic purpoes of IT $_{\text {is }}$ to confine the plasma long and electrons by constraining thern to move in helical orbits about the fleld lines. A transient torotdal current $I_{p} 1 s$ then induced in the conducting plasma by transformer action. This current usually has a quasisteady "flat top" value of several hundred klloamperes for a period of geveraI 
hundred milliseconds. A time-parying vertical magnetic field induced by ohmic heasing $(\mathrm{OH})$ windings around the toroldal direction generates the toroldal current, which heats the plasma via reaistive or "ohmic" heating to a high temperature. In addition, the current produces a poloidal magnetic field (PF) around the smaller cross section of the torus. The net effect of the TF and PF is a hellcal magnetic field as illustrated. This field is characterized not only by the net field strength, but also its rotational transform 2 . This transform is the pololdal angle a fleld line traverses during one toroldal circuit around the tokamak. It is this helical or torsional property of the field lines which gives the tokamak its equilibrium and stability characteristics. A parameter more commonly used than i is the "safety factor" $q=2 \pi / 1$, which depends on $r, B_{T^{\prime}}, I_{p^{\prime}}$ and major radius $R$. The value of $q$ varies with minor radius $r$, and has a strong bearing on the stability properties of the plasma.

The plasma is characterized basically by the temperature of the electrons $\left(T_{e}\right)$ and lons $\left(T_{1}\right)$, typically one to several kev, and electron density $n_{e}$ (typlcal peak value $1-10 \times 10^{13} \mathrm{~cm}^{-3}$ ). These parameters typlcally have large values near the center of the minor cross section, and decrease to small values near the limiter (a metal aperture which defines the plasma aiameter) as 1llustrated in Fig. 2. Also important are the particle and energy confinement times for lons, $\tau_{1}$ and $\tau_{E 1}$, and electrons, $\tau_{e}$ and $\tau_{E e}$. The basic goal of the tokamak is to heat the plasma so that the colliding lons can overcome the repulstve Coulomb barrier (to permit fusion), and to provide sufficlent density and confinement for a sustalned burn, 1.e., heat 1nput from fusion reaction products > power logses from plasma. The temperature required for the easiest fusion reaction to attain, that of deuterium and tritium, is about $10 \mathrm{keV}$ or $10^{8}$ degrees $\mathrm{K}(1 \mathrm{eV}=11,000 \mathrm{~K})$. The required density $\mathrm{n}$ and 
present X-ray diagnostics, some improvements planned for the rokamak Fusion Test Reactor (TFTR) at Princetcn Plasma Physics Laboratory (PPPL), and further development that would benefit the fusion program.

\section{THE TOKAMAK}

At Princeton two tokamaks, the Princeton Large Torus (PLT) and Pololdal Divertor Experiment (PDX) are operating presently. A thira larger machine, the Tokamak Fusion Test Reactor (TFTR) [56], w11l begin operation in 1982. The major goal of TFTR is to achleve "breakeven" (fusion power out = heating power in) in deuterium-beam-heated tritium plasma (DT operation). Several other tokamaks are in operation at other laboratories in the United states and In other countries. These include the Alcator tokamaks at MIT, ISX-B (Impurity Studies Experiment) at Oak Ridge, Doublet III at General Atomic, DITE at Culham, U.K., TFR at Fontenay aux Roses, France; and others in Italy, Germany, Japan, the U.S.S.R., etc.

The tokamak has been revlewed in several papers $[1,48-55]$. A brief description follows. The basic components are show schematically in Fig. 1. A hydrogen-1sutope plasma characterized by major radius $R(130 \mathrm{~cm}$ for PLT, $265 \mathrm{~cm}$ for TFTR) and minor radius $\mathrm{r}=\mathrm{a}(40 \mathrm{cth}$ for PLT, 85 cm for TFTR) is created and heated in a toroldal vacuum vessel. $A$ strong, static magnetic field $B_{T}(1-10 \mathrm{~T}$, depending on the type of tokanak and the regime of operation being otudied) is superposed throughout the vacuum vessel by external toroidal fleld (TF) colls. The basic purpose of $B_{F}$ is to confine the plagma ions and electrons by constraining ther to move in helical orbits about the fleld ilnes. A transient toroidal current $I_{p} 18$ then induced in the conducting plasma by transformer action. This current usually has a quasisteady "flat top" value of Beveral hundred kiloamperes for a period of several 
hundred milligeconds. A time-varying vertical magnetic field induced by ohmic heating $(\mathrm{OH})$ windings around the toroidal direction generates the toroldal current, which heats the plasma via resistive or "ohmic" heating to a high temperature. In addition, the current produces a pololdal magnetic field (PF) around the smaller cross section of the torus. The net effect of the TF and PF is a helical magnetic field as lilustrated. This field is characterized not only by the net fleld strength, but also its rotational transform 1 . This transform is the pololdal angle a field line traverses during one toroldal circult around the tokamak. It $1 \mathrm{~s}$ this hellcal or torsional property of the field lines which glves the tokamak its equilibrium and stability characterlstics. A parameter more commonly used than i is the "safety factor" $q=2 \pi / l$, which depends on $r, B_{p}, I_{p^{\prime}}$ and major radius $R$. The value of $q$ varies with minor radius $r$, and has a strong bearing on the stimility properties of the plasma.

The plasma is characterized baslcally by the temperature of the electrons $\left(T_{e}\right)$ and lons $\left(T_{1}\right)$, typically one to several kev, and electron density $n_{e}$ (typlcal peak value $1-10 \times 10^{13} \mathrm{~cm}^{-3}$ ). These paraneters typically have large values near the center of the minor cross section, and decrease to small values near the IImiter (a metal aperture which defines the plasma diameter) as 1llustrated in Fig. 2. Also important are the particle and energy confinement times for lons, $\tau_{1}$ and $\tau_{E 1}$, and electrons, $\tau_{e}$ and $\tau_{E e}$. The basic goal of the tokamak is to heat the plasma so that the colliding lons can overcome the repulsive coulomb barrier (to permit fusion), and to provide sufficlent density and confinement for a sustained burn, i.e., heat input from fubion reaction products > power losses from plasma. The temperature required for the easiest fusion reaction to attain, that of deuteriun and tritium, 1s about $10 \mathrm{kev}$ or $10^{8}$ degrees $\mathrm{K}(1 \mathrm{eV}=11,600 \mathrm{~K})$. The required density $\mathrm{n}$ and 
confinement time $\tau$ are specified by the Lawson criterion, $n \tau=10^{14} \mathrm{~cm}^{-3} \mathrm{Bec}^{-3}$ [57). Working contrary to achlevement of these goals are several power-108s mechantsms and other processes which tend to cool and destabilize the plasma and prevent attalnment of high temperature, high density, and good confinement $[51,58]$. Power-loss mechanlans include radiation, lonization, charge-exchange logees (a hot ion is neutralized by capturing an electron from a cold neutral atom, and is no longer confined, conduction, and convection. Becauge of the large thernal and density gradients possible and the profound effect gradients can have on cross field transport of energy and particles, spatially resolved measurements, of $T_{e}, n_{e}, I_{p}$, impurity concentration and all other quantities of interest are of great importance.

Because temperatures achievable by ohmic heating are 1 imited to $3-4 \mathrm{keV}$, [51] several auxiliary heating schemes are in use. Injection of Intense beams (up to $3 \mathrm{MW}$ of power) of $40-\mathrm{keV}$ neutral deuterium (D०) atoms into the pLT tokamak $[32,59,60]$ has ralged the Ion temperature from 1 to $7 \mathrm{kev}$. Recently, the lon temperature in PDX was increased from 1 to $5.8 \mathrm{keV}$ by $7 \mathrm{MW}$ of neutralbeam power. Neutral-beam injection experiments have been done on othex tokamaks [61-63]. Heating by absorption of radio-frequency (RF) electromagnetic radiation at geveral resonance frequencies characteriatic of the plasma (like a microwave oven) has been succesafully teated $[32,64]$. Adiabatic compression is another successful auxiliary heating technique.

\section{IMPURITIES}

In addition to the working gas, traces of impurity lons inevitably enter the plasma. These include cxygen and carbon In the $1-108$ range irelative to $n_{e}$ and smaller quanties $(, 03-18$ ) of wall and 1 imiter materials (Fe, Cr, N1, T1, and $\mathrm{Ho}$ ) [65]. Tungsten (w) was also used for Itmiters in earlier times. 
These Impurities can have profound effects, some deleterious and some beneficlal, on the plasma. The 1mportance of these effects is indicated by the extensive experimental [66-100] and theoretical [101-118] efforts by many groups and indtviduals toward understanding impurity transport and impurity effects on the plasma, impurity production mechanisms, and toward developing schemes for reducing impurity influx and removing impurities from the plastna. Recipos for removal of adsorbed oxiggen and carbon from the vacuumvessel wall [119] are used for all tokamaks. Titaniun is evaporated onto walls to cover up adsorbed oxygen [58]. Special low $\mathrm{z} 1$ intters have replaced high $\mathrm{z}$ materials to avold the deleterious effects of high $\mathrm{z}$ impurities in the plasma [58]. Impurity studies and control has been a major emphasis in the PLT research program $[58,60]$. The PDX experiment was constructed to study, among other effects, removal of impurities by a magnetic divertor [50]. The ISX-A tokamak was constructed to do impurity studies and, in particular, to test a concept for preventing impurities from flowing to the center of the plasma $[99,101]$. Theoretical models of impurity transport are used to help interpret experimental data $[62,102,105,111]$. Calculations of radiat1ve power loss have been done for many impurity ions. These results indicate that a $w$ density of .018 of $n_{e}$ can prevent Ignition of DT plasma in a tokanak reactor [107]. Because of the Importance of impurity effects and because a major emphasis of $X$-ray diagnostics $1 \mathrm{~s}$ measurement of impurity radiation and behavior, we give here a brief review of this subject.

As an impurity atom enters a tokamak plasma it is ionized by electron impact to successively higher charge states until a balance is reached between ionization and recombination $[6,112,113]$, assuming steady-state conditions. Under these equilibrium conditions a distribution of charge states exists (F1g. 3). ThIa distribution can be altered by motion of lons from hot to 
cooler regions, or vice-versa, in tokamaks. The most probable charge state typlcally has an tonization potential approximately $1-2$ times $T_{e}$ The disiribution is usually narrow, with 4 or 5 fonization gtages existing at any particular temperature. Thus, in a tokamak, whose temperature varies significantly with radius (Fig. 2), the distrikation progresses continuously from low degrees of lonization at the periphery to higher stages at the center. A given charge state tends to cluster in a ghell of geveral centimeters radius. Ln. $Z$ impurities such as $C$ and $O$ tend to be fully stripped at the center, whereas high $\mathrm{z}$ ions are only partially stripped.

These impurities affect the plasma in several ways. They cool the plasma by causing power to be radiated away via bremsitrahlung, radiative recombination, and line emission (Fig. 4) $[6,52,107]$. This cooling can be deleterious in the plasma center, which we are trying to heat. or radiation cooling of the periphery of a reactor by low $z$ impuritieg can be beneficial; low edge temperatures tend to reduce the influx of higher $z$ sall impurities, presumably by reducing sputtering [32]. The low $z$ impurities are relatively benlgn in the center, as far as energy loss is concerned, 3ince fully stripped Ions produce no line radiation. High $\mathrm{z}$ impurities in the center can radiate profusely because they have several bound electrons which can be exclted $[10,33,34,62,80]$. Several people have been involved in calculations of radiation power from plasmas $[87,106-108,110]$.

Also, impurities increase the plasma resigtivity and can change the plasma-current radial distribution, thereby affecting stab1lity [109,120]. Low $z$ impurities are usually the worst offenders here since high $z$ impurities are typicaliy not present in sufficient quantities to affect the plasma resistivity glgnificantly. As impurity content increases, the range of stable operating tonditions diminishes; the onset of degraded confinement and digruptive ingtabilities occurs at lower density and plasma current [120] . 
A third harmful effect of impurities 18 dilution of the reacting fuel 1ons. The overall effect of Impurities 18 often described in terms of the1r contribution to the effective charge

$$
z_{\text {eff }}=\sum_{i} \frac{n_{1} z_{1}^{2}}{n_{e}}
$$

where che summation lo over gharge states $z_{1}$ of all lons of density $n_{1}$. For a burning plasma the reaction rate of fusion power for $f 1 x e d$ ne and $T_{1} 1 s$ reduced by a factor

$$
f=\left(\frac{z_{I}-z_{\text {efE }}}{z_{I}-1}\right)^{2}
$$

for a single impurit; of charge $z_{I}$, relative to an impurity-free plasma. For a 38 fully strippes $c$ contamination, we get $z_{\text {eff }}=2$ and $f=.64$ whlch corregponds to a 508 increase In the cost of electricity [120].

Impuritles can also reduce the penetration of reutral beame used for auxillary hexiting due to the large cross section for electron capture by highly stripped impurities from deuterium.

\section{X-RAY EMISSION CHARACTERISTICS}

The X-ray emission Bpectrum from tokamaks consists of a continuum with characteristic peaks superimposed. The continum has two components resulting fram electron-1un collisions:

(1) free-free (ff) bremsstrahlung on hydrogen isotopes and impurity ions, and

(2) Eree-bound (fb) recombination of electrons with impurity 1ons. 
The dependence of the continuum intensity on atomic and plasma parameters has been treated in deta1l $[6, \theta]$. For our purposes 1 is aufficient to note that the bremsgtrahlung emisgion is

$$
\left(\frac{\Delta W}{\Delta k}\right)_{f f} \propto n_{e} \sum_{1} n_{1} z_{1 f f}^{2} \quad \exp \left(-k / T_{e}\right)
$$

where $\Delta W$ is the radiated power per $\mathrm{cm}^{3}$ into the photon energy interval $\Delta k$, ne and $n_{1}$ the electron and lon density, $z_{1 f f}$ the lon charge relevant for freefree transitfons ( a nuclear charge), $k$ the photon energy, and $T_{e}$ the electron temperature. For recombination radiation in the energy range above the Ionization potentlal of the recombining ion, we san write

$$
\left(\frac{\Delta W}{\Delta k}\right)_{f b}=\left(\frac{\Delta W}{\Delta k}\right)_{f \in}\left(\gamma_{1}-1\right),
$$

beceuse $f b$ and ff radiation have the same spectral shape. The parameter $Y_{1} 1 s$ the enhancement of the continuum radiation over bremgatrahlung due to the recombination radiation. The dependence of the line radiation spection on impurity content, atoric physics, and plasma parameters has also been treated in detail for some impurities $[118,121]$.

Examples of typical X-ray emiselon spectra from the PDX tokamak and the EBT device at oak Ridge National Laboratory, respectively, are shown in Figs. 5 and 6. Absolute mearsurements of some 1mpurity Ine intensities in the usx reglon have been given [92]. The volumn emissivity of photons varles stronsiy with energy and impurity concentration. Typical values may range from near $10^{15} \mathrm{~cm}^{-3} \mathrm{Bec}^{-1}$ for the Ni XXV $118 \AA$ line [92] to $10^{13} \mathrm{~cm}^{-3} \mathrm{gec}^{-1} \mathrm{keV}^{-1} \mathrm{and}^{10^{9}}$ $\mathrm{cm}^{-3} \mathrm{gec}^{-1} \mathrm{kev}^{-1}$ for the continum at 1 and $10 \mathrm{kev}$, respectively, for a plasma 
with $T_{e}=1 \mathrm{keV}$ and $n_{e}=5 \times 10^{13} \mathrm{~cm}^{-3}$. we see that ilne and continuum intensities can vary by many orders of magnitude over the spectral range of interest. Thus X-ray diagnostics must cover a wide dynanic range. We make three general observations:

(1) The continuum spectrum has an exponential dependence on photon energy. The slope on a semilogarithmic plot $1 \mathrm{~s}-1 / \mathrm{T}_{\mathrm{e}}$. Using this we can measure $T_{e}$ from the continuum spectrum.

(2) The intensity of the continuum depends on the relevart lon charge $z_{1}$ as $n_{i} z_{i}^{2}$. Thus a relatively small lon fraction $n_{1}$ can produce a relatively large contribution ince $\mathrm{z}_{\underline{1}}^{2}$ is typlcally large.

(3) The enhancement factor $\gamma_{i}$ is $t$,pically $\approx$ 10 for clean discharges [8, 15] but under some circumstances can be as large as $\sim 1000[15,36]$. This factor depends strongly on the lonization stage of an inpurity ion [6]. Thus for a quantitative evaluation of the continuum, the lon densities and charge-state distributions must be known.

\section{X-RAY DIAGNOSTIC INSTHUMENTS}

There are several types of X-ray diagnostla used for tokanak research. Each has 1ts own purpose based on its charantarlstics. These include: (1) energy range, (2) energy resolution, (3) time resolution, and (4) spatial resolution.

In the following sections some of these instrunents will be described. Their principles, geonetry, mode of operation, characterisulcs, and examples 
of data with some interpretation will be presented. The grazing incidence diffraction-grating spectrometer, traditionally considered a vacuumnltraviolet (VUV) Instrument, will be Included since Lmportant work tin the low energy $X-r a y$ region has been done using this instrument.

Briefly the instruments to be described and their basic characteristics are as follows:

(1) Pulse-Helght analyzer (PHA) - wide spectral range, moderate tIme and energy regolution, and moderate spatial resolution.

(2) X-ray crystal spectrometer (xcs) - Narrow spectral range, very good energy resolution, and moderate time and gpatial regolution.

(3) X-ray Imaging system (XIS) - broad spectral range, crude energy resolution, very good time resolution, and good spatial resolution.

(4) Rotating crystal spectrometer (Rer, - moderate spectral range, good energy resolution, moderate to good time resolution, and moderate spatial resolution.

(5) Grazing Incidence Spectrometer and Monochromator (GISmo) - broad spectral range, good time resolution, good to very good energy resolution, and good spatial resolution.

(6) Other Instruments with varloug characteristics. 
The diagnogtic names, acronyms, and 1ngtrument degcriptions to follow are characterlstic of 1nstruments used at PFP in the X-ray group and UV, visible spectroscopy group. S1milar types of dlagnostics, however, are used at rany other laboratorles.

\section{A. PULSE HEIGHT ANALYZER}

The Pulse-Helght analyzer (PHA) X-ray dlagnostic is a very useful and versatile instrument. It 1 s used on many present day tokamaks $[6,13,15,17$, 18, 30, 123] and other Fusion experiments [122]. It provides a broad overview of the $\mathrm{X}$-ray emission and yleids temporally and spatially resolvea measurements of $T_{e}$ from tine slope of the continuum, high and low $z$ impurity concentration (from regpectively, Impurity line intensities and enhancement of the cortinuum over bremsetrahlung via recomblnation), and information on nonMaxwellian features of the electron-velocity distribution [6]. Sample FHA spectra have been shown in F1g. 5. The $\mathrm{X}$-ray energy range at PPPL has historlcally been $11 \mathrm{mlted}$ to $1-30 \mathrm{keV}$ because of beryllium vacuum windows and thin lithium-arifted silicon or $S I(L 1)$ detectors. Recently, however, the PHA on PDX has been extended to the sub-kilovolt region by implementation of a windowless $S 1(L 1)$ detector. Th1s type of detector has already been in use at other laboratories [12.2]. Figure $i$ illusirates the principle of the PHA [6]. The PHA may consist of one pivotable tube (for spatial scanning) or several tubes to view several regions of the plasma simultaneously. In each tube a set of collimaters directs the $X$ rays to one or more $S($ I 1 ) detectors. Mult1-detectors are used to improve the time resolution and statistics by increasing the net count rate of the system. The main technical limitation here is pulse plle-up at high rates $[6,14]$ (two pulses arriving simultaneously at the detector are additive and reglster as one pulse at 
higher energy). The effects of pulse pile-up are exacerbated by the exponentially decreasing continuum spectrum. A few plled-up low energy pulses, due to high intensity, can cause a relatively large distortion of the spectrum at higher energy where the count rate ts much lower. The PHA minimizes this problem by conetralning, by means of absorber follo and apertures, each of several detectors to focus on a portion of the total spectrum. The loni-energy detector has a thin foll to pass low energy radiation and a small aperture to reduce the count rate to an acceptable range. Higher energy channels have succegsively thlcker folls and larger apertures to equalize count race. From the partlal spectra from each detector the computer synthealzes a single total spectrum by

(a) correcting each spectrum for 1ts absorber ald aperture gize,

(b) discarding the higher energy portlons which may be susceptible to pileup distortion, and

(c) overlaying the separate spectra (mathematically) on a common scale. Four composite spectra measured from four different chords of the PDX tokamak are displayed in Fig 5. The energy resolution of the PHA must be $\sim 200 \mathrm{eV}$ FWHM at $6 \mathrm{keV}$ to permit separation of $K_{\alpha}$ impurity peaks from Fe, Cr, and Ni. These peaks are ghifted toward higher energy, relative to the $K_{\alpha_{1}, 2}$ pals, and broadened because of the distribution of emitting charge states [21]. Good energy resolution 18 also important tc peimit separation of peaks from the continuum so that undistorted reglons of the continum are ayallable for $T_{e}$ disternination. To obtaln time resolution, sixteen or more spectra are taken during a single 1 -gecond discharge. Th1s time resolution is Iinited at present to about $50 \mathrm{~ms}$ by (a) the need for reasonable statistics in a spectrum, (b) count-rate Iimitations of the atectorg at the required energy resolution, and (c) the maximum number of detectors which can reasonably be 
used in one PHA tube. The PHA on PLT has Four detectors $[6,9]$, PDX hag three detectors per tube for each of five tubes $[30]$, and the TFTR PHA will have eight tubes each with six detectors [125]. Any improvement in the time resolution such as by improvement of pulse-pileup rejection, development of hlgher transconductance FET's [126] etc., would be welcomed.

Figure 6 is a nice spectrum fror. the 5-detector $S 1(L 1)$ array on EBT showing a prominent al $\boldsymbol{K}_{\alpha}$ peak [122]. The continuum slope indicates a $T_{e}$ value of $850 \mathrm{ev}$.

B. THE X-RAY CRYSTAL SPECTROMETER

Crystal spectrometers have been used for detalled investigations of Impurity line radiation in both the soft $x$-ray region (Sx) and the ultra-soft $x$-ray (USX) reglon. Wavelength scanning (point by point) flat crystal spectrometers and curved crystal multiwavelength polychrometers will be treated in this section. A newly developed dynamically rotating flat crystal spectrometer w1ll be described in a separate section.

Shot-to-shot scanning of $X$-ray spectra using flat crystal spectrometers has been used both on A-pinches for measurement of Impurities [127] and for investigation of temperature diagnostics by measurement of dielectronicrecombination line intenstties [45], and on tokamaks for separation of $\mathrm{K}_{\alpha}$ radiation from different charge states of Fe [128], for Investigation of oxygen $K$ and Fe $L$ spectra in the region .5-1 keV [6], and for measurement of Mo and $a 1$ emission [82]. Curved crystal spectrometers which are much superior =o the scanning flat crystal Instruments have been developed recently. These have ruch higher intensity and are equipped with a position sensitive detector with ilows gimultaneous measurement of an entire spectrum, avoiding the pEDolems zesciated with shot-to-shot reproducibility [21]. While these 
Ingtruments have so far been used only in the $5 x$ region, the principle 19 capable of extension to the USx region, although complicationg exist. These inciude: (1) operation in vacuum, (2) use of thin window or windowless detectos.6, and (3) more severe limitations on resolution because of the relatively broad $(E / \Delta E \approx 2000)$ crystal rocking curves.

The multiwavelength Johann curved crystal spectrometer, recently dubbed $\mathrm{X}$-ray Crystal spectrometer (XCS), was f1ret used on tokamaks (PLT) with $\mathrm{f} \pm 1 \mathrm{~m}$ recording [129] for 1nvegtigation of Fe $K_{\alpha}$ spectra. Subsequently, an tmproved version with time-dependent readout using a position-senstive multiwire proportional counter was developed [21]. The pxinciple of operation of this xCS is 1llustrated in Fig. 8. Also shown is a crystal mounted in a jig used for bending and holding it to a cylinarical shape. $x$ rays from the plasma pass through a vacuum tight beryllium window inte tubes filled with nelium to minimize $x$-ray attenuation. $x$ rays of different wavelengths $\left(e . g ., \lambda_{1}\right.$ and $\left.\lambda_{2}\right)$ from different parts of the plasma are diffracted according to the Bragg relation $n \lambda=2 d \sin \theta(n=$ order, $\lambda=$ wavelength, $d=$ spacing of crystal lattice planes, $\theta=B \bar{y}$ agg angle) and focussed to corresponding points on the Rowland circle of radius $R$. The range of wavelengths or energies which can be covered during a single integration period 18 determined by the crystal angular dispersion, the detector lengtin $l$, and the crystal-to-detector distance $R \sin \theta$,

$$
\frac{\Delta E}{E} \approx \frac{\ell}{\operatorname{Re} \ln \theta} \cot \theta .
$$

The energy resolution 1 s determined by the position resolution of the detector, the distance from crystal to detector, and the crystal rocking-curve w1dth. 
The XCS was first used on PLT to study the charge-gtate distribution of Fe XVIII - Fe XXV lons [21]. A knoinadge of this distribution 1s important for (3) absolute measurement of Fe concentration from the Fe peak of the PHA spectrum (since excitation rate varies with charge state), (b) realistlc studies of transport of $\mathrm{Fe}$ ions, and (c) veriflcation of theoretical excitation and recombination rates. As the central electron temperature $T_{e}$ (0) Increases the Iron is lonized to a higher charge state, and the spectrum shifts to higher energles (FIg. 9).

For these measurements an XCS w1th $R \approx 5 \mathrm{~m}, E / \Delta E \approx 1700$, and using a Ge (220) crystal was used. The spatial resolution of the proportional counter was $.4 \mathrm{~mm}$. To obtain time resolution of $\sim 50 \mathrm{~ms}, 15$ spectra can be recorded durfing a 1 second discharge, altinough data from several similer discharges may have to be added for reasonable statistics.

More recently the XCS on PLT was greatly imfroved by substitution of an $\alpha$-quartz (2243) erystal with $R=3.33 \mathrm{~m}$ to provide d resolving power $E / \Delta E=15000$. An Fe spectrum meassured with this spectrometer is shown in Fig. $10[22,37]$. The peaks shown include resonance lines of Fe XXIII - Fe XXV $(\beta, q, w$, respectively), forbidden $(z)$ and intercombination $(x, y)$ lines of $F e$ xxv, and lithium-like satellites exclted mostly via dielectronic recombination.

This ultra-high resolution XCS was developed mainly to measure ion temperature $T_{1}$ by Doppler broadening of the Fe $x \times v$ hellum-11ke resonance 11ne w. Aimilar high resolution $(E / \Delta E=23000$ ) XCS using an $\alpha$-quartz (2023) crystal has been Installed on the PDX tokamak at PPPI for $T_{1}$ measurements and other invegtigations using $X$ rays from highly lonized titanium lons. As shown In $51 \mathrm{~g}$. 11 this spectrometer has measured fon temperatuce 1ncreases from $\sim 1.0$ to $5.8 \mathrm{keV}$ resulting from $\sim 7 \mathrm{MW}$ of NBI heating. This figure shows the time 
history of $T_{1}$ as inferred from Volgt-function $f 1 t s$ to the Doppler broadened titanium XXI 1s-2p resonance line.

Detalled studies of intensity ratlos of various peaks indicated in Fig. 10. ralative to Iine $w$, as a function of $T_{e}$ and $n_{e}$ have demonstrated several other useful aspects of the high-resolution spectra. These include measurement of $T_{e}$ from the ratio $I_{j} / I_{w}$, the departure of $F e$ charge atates from ionization equilibrium, dielectrontc recombination rateg, and impurity transport rates. Theoretical work by Gabriel and coworkers was used as a basis for some of these measurements [37]. The TFR Group has recently reported similax stuales in the Usx region for oxygen lons [124].

A diffarent type of hign resolution crygtal spectrometer using the design of von Hamos and a resistive-anode posttion sensitive proportional counter has recently become operational on the Alcator $C$ tokamak at MIT [130]. Measurements of $\mathrm{Cl}$ and $\mathrm{S} \mathrm{K}$ spectra have been reported. $\mathrm{A}$ higher resolution version hag just been implemented for ion-temperature determination [131].

The 1mportance of the $x C s$ for $T_{1}$ measurement increaseg for larger, higher denstty future tokamak plagmas. Other $T_{1}$ measurement techniques will become severely limited for reactur plasmag [5].

\section{THE X-RAY IMAGING SYSTEMS}

Development of the technique used for the $x$-ray Imaging systems (xts) has revolutioni sed the study of magnetohydrodynamic (MHD) plasma instabilities or fluctuations in tokamaks. Use of this technique of measuring $x$ ray fluctuations in tokamaks has been actively pursued at many laboratories since about $1972[23-27,132-138]$ when "gawtooth oscillations" were aiscovered in the Intensity of X-Iay emlsaton from the ST tokanak, as measured by a two-detector syatem [132]. Because of the profound effect (deletertous in some cases and 
beneficial in others) the varlous modes of oscillation can have on plagma particle and energy confinement, MFE theorists and experimentalists have devoted much effort to measurement and interpretation of these fluctuations [23-27,132-139]. In addition, the xIs ras been extremely useful in characterizing the effects of impurity radiation on tokamak behavior and understanding the behavior and means of controlling impuxities [10]. Various investigators have also used the XIS technique on tokamaks to measure plasma toroidal rotation [6], electron heat conductivity [140], and dielectronic recomblnation coefficients of impurity lons [47]. A Further use $1 \mathrm{~s}$ measurement of plasma position.

The principle of the XIS is illustrated in Fig. 12. It is essentially a slot hole $x$-ray camera. An array of $x$-ray detectors views the plagma through a slot, permitting measurement of the line integrated $x$-ray intensity from several chords of the plasma. This $x$-ray intensity is modulated by rapid dengity and temperature varlations which arcompany the propagation of waves or fluctuations through the plasma. The detectors are typlcally silicon surfacebarrler or PIN diodes, operated in current mode. The $x$-ray energy range of sensitivity of the dlodeg is usually limited to greater than $.1 \mathrm{kev}$ by absorption in a gold contact layer, typlcally $40 \mu \mathrm{g} / \mathrm{cm}^{2}$, and a 510,2 dead layer, typlcally $7 \mathrm{\mu g} / \mathrm{cm}^{2}$, on the surface of the detector. The transmission of these layers is glven in Ref. [6]. The high-energy efflclency depends on the effective thickness of the deretor. Rough estimates of the spectral composition of the radiation are obtalned by inserting absorber foils into the X-ray path. Reference [6] shows the transmission factor for varlous folls used on the PLT XIS.

The time scale for fluctuations in tokamaks rangeg from the millisecond to the microsecond range. Typical currents generated in the detectors range 
from a few nanoamperes to tens of microamperes. Thus the current in the detectors must be amplifled by low nolse, wide band amplifiers. Typical nolse levels aze .3 $\mathrm{nA}$ rms for a $500 \mathrm{kHz}$ bandwidth [6]. The current is recorded by transient digitizers at rates of a few $\mathrm{kHz}$ to $1 \mathrm{kHz}$ or stored on magnet1c tape for later analysis. On PLT the digitizing rate is switchable during the plasma shot, In order to permit measurement of details of fast phenomena such as alsruptions.

Figure 13 shows typlcal data from several detectors of the imaging array on PDX during a portion of a discharge. Graphed is detector current or line integrated $x$-ray emissivity as a function of time. The stars indicate both chord radius and the zero intensity level for that chord. An m=1 oscillation of the plasma column about its equilibrium position occurs, where m refers to the mode number of a Fourier expansion of the displacement in the pololdal angle $\phi$. From these data we can also construct the tine dependence of the radial emissivity profiles ds shown in Fig. 14. These particular nu=1 osciliations were caused by neutral beam heating.

Emission in the ultra-soft $x$-ray (USX) range $(0.1<E<1 \mathrm{keV}$ ) is often a significant energy-lose mechanism and an excellent medium for monitoring particle transport and magnetic fleld evolution. A detalled presentation of the use of the broadband XIS arrays for gtudy1ng the UsX with good gpatial ( $1 \mathrm{~cm})$ and temporal $(\sim 1 \mathrm{~ms}-1 \mu \mathrm{s})$ resolution has been given by Eames $[10]$. Several interesting and significant phenomena have been observeă. For example rf heating at the ion cyclotroi frequency (ICRH) resulted in a factor of 2.5 Increase in the influx of both Fe and deuterium into the plasma, with little change in confinement time $(\tau \approx 40 \mathrm{~ms})$. With neutral beam injection in the direction opposite to the plasma curcent, evidence was noted of an increase in both the tungsten flux and its concentration at the center of the plasma. The 


\begin{abstract}
power-emission density at the center of the discharge was a very large $2 \mathrm{~W} / \mathrm{cm}^{3}$ just before a disruption occurred. The tungsten concentration, relative to $n_{e}$, was frur times larger at the center than at one half the minor radius.

Another unugual observation was inverted "sawtooth" oscillations in the USx emission. While the goft $x$-ray (Sx) emission ( $E \geq 1 \mathrm{kev}$ ) decreases at the center, the USX radiation increases. Sawtooth oscillaticas are explained as a cyclic process in which the plasma is preferentially heated in the center causing the soft $x-r a y$ emisgivity to slowly rise and the current to redistribute to a more peaked profile $[23,26]$. At some point MHD or microstability processes become unstable, and the peak collapses or flattens, the energy being rapidly transported outwards. Tila causes a sudden drop in soft $x$-ray emiasion near the center where the temperature arops atid a sudden rise in enission at large racil where the heat is deposited.
\end{abstract}

A puzzling observation was that of so-called "Implosive" disruptions [10;. During the more commor, "explosive" disruptions both the USX ard the Sx (FIg. 15) emisslons decrease rapidly at the center and tncrease at the edges. This is suggestive of a movement of the plasma outward from the center, hence, the name "explosive." During "implosive" alsruptions, while the Sx emission exhibits the usual behavior, the usx emisgion increases at all radii iflg. 16). The increase at the center is guggestive of movement of the plagma toward the center, from which the term "implosive" derives. Also observed during the implosive alsruption are an asymmetric soft $x$-ray flash lasting for 10-20 HB $^{\mathrm{B}}$ and a simul'aneous doubling of the USX emission $\mathrm{c}$ er the plasila cross section in $10 \mu s$. The soft $x-r a y$ flash is belleved to be due to conversion of magnetic energy into kinetic energy. The doubling of the usx enission over such a short time scale was somewhat difficult to explain. A tentative explanation is enhanced oxygen radiation $[10]$. 


\section{THE ROTATING CRYSTAL AND GRAZING INCIDENCE}

SPECTROMETERS

The recent development of the Rotating Crystal spectrometer (RCS) $[10,141]$ at PPL has caused a tremendous increase in the volume of high resolution USX de'ta measurable from tokamaks, as compared to grazing-1ncidence grating spectrometers. The gmall size, light weight, and relative simplicity of construction of the RCS all represent significant improvements in versatility and in suitablilty as a multichordal instrument for tokamak measurements. Even so, the RCS is by no means a replacement for the grazingincldence grating monochromazor and spectrometer (GISMO) which has been used for decades for high resolution spectrometry of MFE plasma. Rather, the tw? Instruments are complementary, with GIsMo extending to longer wavelength ard providing sbsolute intensity measurements. GIsMo is compared with the RCS here only because the two instruments partially overlap in spectral range and are used for sirilar purposes.

The RCS can scan the entire spectrum from 500 eV to 2 kev with good energy resolution $(E / \Delta E=400)$ twenty times during a tokamak discharge, giving a time resolution of $50 \mathrm{~ms}$. Alternatively, the RCS crystal can be fixed at one setting to provide very good time resolution for one spectral point. The GISMO-type instrument using illm instead requires twenty discharges to cover the range 200-1000 eV. Using photoelectric readov: the GISHO can measure the Intensity at only two points of the entire spectrum during one discharge, oo that many discharges would be required to scan the entire spectrum. The Rcs, however, may present some problems with regard to absolute calibration since 1ts detector, a serles of microchannel plates, has rapla variations in effictency as the angle of incidence of the radiation is varied. 
The RCS is shown in Fig. 17. A soller collimator limiti the angular divergence of the radiation from the plabma to roughly .1 degree. $A$ set of absorber foils of $1 \mu \mathrm{m}$ parylene and .6 $4 \mathrm{~m}$ Al reduces background due to intense radiation at wavelengths longer than $26 \AA$ [141]. The radiation 13 Bragg cirfracted from a TAP or AdP plane crystal and detected by a set of four Chevron microchanne: plates (MCP) arranged on a semiclrcle. The front surface of each MCP pair has a MgF, coating io enhance its sensitivity to soft $x$ rays. The aignal output consists of current to the collector plates. In order to obtain spectra the crygtal is rotated, typically at 10 revolutions pler second, and the collector current is measured as a function of time. Tire energy calibration, 1.e., the Bragg angle, 1s determined by interrupting the light from an IID to a photodetactor by a slotted disk which rotates oynchronously with the crystal.

Figure 18 shows output traces during a plasma shot recorded with a transient analyzer. Traces (a) show the signal from the photodetector, which $1 \mathrm{~s}$ produced by the slotted disk interrupting the light beam from the LED. One of the slots has been covered to provirle a reference for angle determination. Figure $18 \mathrm{~b}$ ahows the current to the collector plates of the MCP. Spectra are produced alternately by the TAP and the AdP crystal. The spectra with higher intensity are from the TAP crystal, which spans the wavelength region 10-17 \& where the iron $L$ radiation is located. The two lower spectra show Iron I lines on an expanded time scale early and late in the discharge. During the early times Fe wil 1 ines are dominant $(t=109-110$ ms). Later all Fe charge states are present (t = 309-310 ms). Figure 19 shows an Fe I spectrum late during a PLT discharge. Peak identifications were made from identiflcations of prominent Fe $I$ lines in solar flare and laser plasmas $[10,141]$. Another spectrum from an oxygen-rich discharge is shown in 
F1g. 20. $z$ tilting the RCS about a pivot polnt, hordal proflles of $x-x a y$ emission can be measured. Figure 21 shows such proflles of several major 1 ron L transitions for different charge-atates.

The grazing thcleence diffraction grating spectrometer and monochromator has long been used as a standard diagnoatic for monitoring radiation from tokamak plasmag, both in the low energy $X$-ray region and at lovex energies ( $t$ (.1 kev). These instrumentg are commerclally avaliable and are described in the literatire [29]. Both photographlc (broadband, time-integrated) and photoelectric (one or two narrow wavelength reglons, time-resolved) detectlon h sve been used $[63,79,80]$.

Comparison of photographlc spectra from ormax with theoretical calculatio. for emission Erom tungaten $x \times x I-x \times x V$ Identified $\omega$ t $n=0$ tiansitions as the source of intense pseudo-continue in the 40-70 $A$ region [20j. Sintlar paeudo-continua near $50 \mathrm{~A}$ and other bands at ionger wavelength have also been observed in the Japanese tokamak oIVA $[34,35,94]$. These continua are evidently largely due to thousands of unresolved $\Delta n=0$ transitions involving the $4 d$ electrons of several charge states of tungsten. In ORMAK [80] and PLT [33. these bands of radiation often accounted for 40-808 of the radiated power and led to or contributed toward undesirable effects such as poor confinement and hollow temperature proflies ( 2001 central plasma). It was possible to reduce the tungsten content through cooling of the plasma edge by adding small amourts of nean or oxygen, or by approprlate p'ograming of the hydrogen influx. Theoe experiments ldentifying tungeten as a malefactor, and zurther experiments with tungsten limiters replaced by low $\mathrm{z}$ limiters of stainless steel and carbon fwhich ylelded mich more favorable plabma behavior), led to the pollcy at PPPL [58] and orkL of excluding high 2 materials from the interlor of tokamaks. 
Grazing Incident epectroneters are routinely used to monitor the ov'. and OVIII radiation at $21.6 \mathrm{~A}$ and $18.96 \mathrm{~A}$, respectively. An interesting rapid Increase in intensity of the OVIII 102; line from ORMak coincident with neutral beam injection has been interpreted to be the result of charge transfer from hydrogen (whose density is increased significantly by the beams) to $0^{7+}$ ions in excited states [63]. Anomalously high (relative to excitation by electrons) 1ntensities of the 115.8-A line of $0^{5+}$ and the $81.9-\AA 11$ ne of $0^{6+}$ in ISx-A have been attributed to excitation via charge transfer from hydrogen atoms into excited states of $0^{\text {n+ }}[79]$.

\section{E. OTHER X-RAY UIAGNOSTICS}

The flltex-detector scheme has long been used for measurements of $x$ rays from plasmas $[3,7]$. A major defect of this method for temperature measurement 1s the uncertainty of interpretation and interference from impurity radiation.

The gas proportional counter has also been used for tokamak x-ray spectroscopy [142]. The energy resolution is poor making it difficult to separate $R_{\alpha}$ peaks from Fe, $C$, and Ni. The gas scintillation proportional cointer (GSPC) [143], however, has better resolution, although not as good as the $S i(L 1)$, and high rate capability. Because of its radiation-damage resistance, it may be good for reactor-plasma $T_{e}$ measurement where good energy resolution is not so critlcal. Photoelectron spectroscopy has been used to deduce the carbon content in the center of the $\mathrm{T}-4$ tokamak [67] following electron capture by CVII frow hydrogen. Thts technique may have further application. 
VI. FUTURE DEVELOPMENTS

The controlled fuslon research program has always suffered from insufficient information on plasma behavior. Designing ingtrumentation to provide ideal unamblgious data has always been an elusive goal, often two or more schemes are developed to measure one plasma property, and neither method is fully adequate, e.g., $T_{e}, T_{1}, n_{e}, T_{p}(r)$. In addition the research effort has often suffered from a shortage of money, manpower, time, and particularly physicists and engineerg with the appropriate expertige to develop optimal diagnost1es. The trend at PPPL recently hag been more toward elther hiring specialists in particular areas of physics relevant to the development of needed diagnostics, or tapping the pool of expertise external to the fusion program through cooperative development efforts, subcontracts, DoE sponsored contracts to outside laboratorles, etc. Such collaborative efforts are certainly benefical to the fusion effort and are probably beneficial, for various reasons, to the external parties involved. The MFE X-ray diagnostics program has several areas where improvements in ingtrumentation and techniques and new creative tdeas for measurements would be welcomed. In the following paragraphs I will discuss some improvements in X-ray instrumentation that are desirable, some of which are currently belng developed for TFTR.

In former times when tokamaks were smaller and diagnostlcs fudgets were leaner than today, many experiments required ahot-to-shot adjustment of spatial view or ifme windows to get adequate spatial or temporal information, or accumulation of data over several shots to get usible statistics. In view of the magnitude, cost, importance, and more urgent nature of future fusion experiments such as TFTR and MFTF-B, such arduous, time-consuning approaches are no longer practical. This is eepecially true for operation of full tritiun plasmas in TFTR (the crucial experiments), since the maximum number of 
such discharges $1 \mathrm{~s} 4000$ and is limited by the allowable tritiun inventory on site and neutron activation. Thus the hope for TFTR $X$-ray alagnostics and others, 18 to have several spatial channels and to improve throughput in each channel so that statiatlcally significant data can be recorded during each shot with oultable spatial and temporal ret--ution.

Much of the development required for TFTR $x-r a y$ diagnostics is associated with the increased radiation levels expected during neutral beam injection (NBI) heating as compared to present-day tokamaks. For $45 \mathrm{MW}$ (beam power) $D D$ plasmas a $2.5-\mathrm{MeV}$ neutron $\mathrm{flux}$ density of $10^{11}$ neutrons $/ \mathrm{cm}^{2} / \mathrm{sec}$ is expected near the tokamak for a 1 second pulse. For DT plasmas a flux density of $6 x$ $10^{13} 14-\mathrm{MeV}$ neutrons/ $\mathrm{cm}^{2} / \mathrm{sec}$ is predicted. These neutron intensities can quickly damage solid-state detectors. The neutrons and concomitant secondary gamma rays from the tokamak structure and concrete walls can generate background nolse levels in detectors which completely mask the $x$-ray slgnals. Thus all $\mathrm{x}$-ray diagnogtics are being redesigned to Include extensive neutron and gamma-ray shielding and collimation to maximize the signal to noise ratio. For the XIS, fast gridded lonization chambers are being developed because of thelr resistance to radiation damage, to replace the easily damaged silicon surface barrier detectors.

The TETR PHA will view more (8-12) radial chords than previously for PLT (1-chord) and PDX (5-chordg). To accommodate the larger range of $T_{e}$ and thus intensity, and to improve time resolution, 2 combination of more detectors per channel (6 vo 3 or 4) and faster electronics is belng 1mplemented. One germantum detector per channel will be added since higher energy $x$ rays $w 111$ be produced by the higher temperature plasmas. since overall rellability decreases as the number of detectors Increases, and a vacuur fallure is potentially more serlous, detector passivation techniques 
will be developed to lmprove the probabllity for detector survival under adverse conditions. Fourteen-MeV neutrons can generate large pulses (up to 11 MeV) In $5 i(L 1)$ detectors. Speclal precautions must be taken in the design of electronics to prevent saturation or overloading by these pulses. The anount of remote control, monitoring, and tegilng, $s$ being increased due to the higher degree of complexity and sophistication and the reduced accesgibility of the diagnostics. Tokamak diagnostics have always had to be more rellable and automatic than laboratory instruments because of remote operation and limited accessibility. Th1s will be even more true for TFTR.

Some further improvements planned for the TFTR XIS are more detectors, an infrared-emitting diode for system testing and comparison of detector responses, a remotely movable standard detector for calibration of fixed detectors during operation, division of the amplifier into two modules with the first (preamplifier) directly on the detector feedthrough to reduce electrical pickup and minimize input capacitance, and a wider range of gains in the electronics. Because of the tremendous data-generating capacity of the XIS when algitization rates up to $500 \mathrm{kHz}$ are used 1240 detectors $\times 5 \times 10^{5}$ words/detector/sec), mass-gtorage techniques have been investigated. A gcheme using EM multiplexing was devised to atore data from up to 320 detectors at $500 \mathrm{kHz}$ bandwidth on a 42-track high speed analog tape recorder. Up to 00 shots per reel could be stored for later playback and aigitization.

Developments for the TFTR XCS include improving time resolution by : zans of higher $\mathrm{x}$-ray fluxes at the detector. This will be achleved by (1) using lower $z$ seed impurities, such as argon, which radiate higher photon fluxes and produce usable slgnals at lower $T_{e}$ (this enables us also to make measurentents further from the plasma center where $T_{e}$ 1g lower), (2) increasing the crystal and detector 3ize, and (3) choosing crystals with higher reflectivity. To 
accommodate higher $x-r a y$ intensity, fagter detectors and electronics are being developed. The larger dynamic range provided by these improvements will be important for TFPR since the temperature excursion during a discharge (and thus the range of $x$-ray $f(u x)$ wil be large due to Intenglve neutral beam, rf, and compression heating.

Grating monochromators are belng converted to polychromators by use of multi-element detectors such as the intensified Reticon photodiode array $[145]$

There is need for further improvement of $x-r a$ : diagnostlcs both for near future experiments such as TFTR and for future reactors. The need for higher count rates haf been mentioned. Shielding and collimation will just prevent damage to the PHA $S I(L I)$ detectors over the life of TFTR $\left(\sim 10^{10}\right.$ neutrons/ $\mathrm{cm}^{2}$ ). Reactors, however, will have much higher duty cycles. Thus the cetectorg will have to either withstand neutron fluences two orders of magnitude higher than present si(Li) detectors can, or be exposed to the reactor only for brlef periods to make a measurement. A possible replacement detector is the gas gcintillation proportional counter [143]. Improvement of reflectivity and resolution of multilayer synthetic crystals would make them attractive for extension of the rotating crystal spectrometer to longer wavelength. The present design of the TFTR X-ray imaging array (XIS) makes it sultable for operation with DD plasmas only. Use of the lonization chamber only hardeng the systen for DT aurvival; in DT operation background nolse levels from radiation w1l render the system inoperable. For a DToperational XIS further development muat be done. The detectors must be moved further from the plasma and more extensively ghielded. In addition reflective $x$-ray optics, such as grazing incident mirrors or Bragg crystals will probably have to be uged to permit removal of the detactor from direct view of the neutron- 
emitting plasma. One candidate for an limproved detector for both the XIs (radiation resistance) and the xcs (high count rate, good position resolution) is the microchannel plate preceded by a high efficiency $x$-ray photocathode. Solid photocathodeg are not sultable. porus photocathodes of csI have demongtrated high efflclency [144]. Further work must be done, however, to answer questions about their rellability, construction, degradation with use, efflclency, etc.

VII. SUMMARY

The Tokamak is a major contender for demonstration of controlled fusion as an eventual power source. x-ray diagnogtics are an important part of the experimental effort. These instruments permit measurement of plasma conditions from varlous aspects of the continuum and line radiation due largely to impurities in the plasma. Soft $x$-ray alagnostics range from (a) instruments with moderate energy and time resolution, which provide an overview of the soft $x$-ray emiggion and a measure of electron temperature and impurity concentration, to (b) those with very good energy resolution and moderate time resolution, which measu-e fon temperature, impurity charge-state distributions, low energy impurity radlative power and other parameters, from details of Impurity spectral line proflles, to (c) instruments which view many spatial chords simultaneously with very fast time response but crude spectral resolution to monitor low energy impurity radiation and fast fluctuations in $\mathrm{X}$-ray emission due to MHD Instabilities.

Development required for near future tritium-burning tokamaks includes shielding and collimation of neutrons and gamma rays, development of radiation-hard detector substitutes in some cases, and 1mprovement of instrumental throughput. Problem areas are limited count rate for detectors 
and electronics, high response to background radiation, low crystal reflectivity, and broad crystal rocking curves in the low energy $x-r a y$ region. For reactors, radiation damage susceptibility will preclude use of all solid-state detectors for direct view of the plasma; sutstitute measurement schemeg must be developed.

VIII. ACKNOWLEDGMENTS

The work reported here would not have been possible without the assistance of W. Mycock, J. Gorman, and the PLT and PDX physicists and operating crews. Speclal acknowledgment 18 due to Drs. H. Furth, M. Gottlieb, and $\boldsymbol{~}$. Stodiek for continuing support. This work supported by Department of Energy Contract No. DE-AC02-76-CHO-3073. 
REFERENCES

[1] IEEE Spectrum, New York (December 1, 1980; p.1.

[2] 5. Stndont and $c$. Wharton, eds., Diagnogttc6 Eor Euston Expertiments, (Pergamon Press, New York, 1979).

[3] T.F. Stratton in Plasma Dlagnostics Techniques, edited by Huddlestone and Leonard, (Academic Press, New York, 1965) 359-397.

[4] C.B. Wharton, In Physics Today, 52 (May 1979).

(5] Equipe TFR, Nucl. Fu Ion 18, 647 (1978).

[6] S. von Goeler, in Diagnostics Eor Fuston Experiments, (Pergamon preas, New York, 1979) 79-109.

[7] C. de Michel1s and M. Matt1ol1, "Soft X-ray Spectroscoplc Diagnostics of Laboratory Plasmas," EUR-CEA-FC-1084 (Merch, 1981) 207 pP.

[B] S. von Goeler, W. Stodlek, H. Eubank, H. Fishman, S. Grebenshikov, E. HInnov, Nucl. Fuston 15, 301 (1975).

[9] S. von Goeler, N. Sauthoff, M. Bitter, K. Brau, D. Eames, B. Fraenkel, A. Greenberger, K. Hil1, R. Horton, G. Hovey, J. Hovey, W. Roney, H. Stodiek, "Soft X-ray Measurements on the PLT Tokamak," PPPL-1383 (1977) $15 \mathrm{pp}$.

[10] D.R. Eames, "Ultra-soft $X-r$ ay Enission from the Princeton Large Iorus Tokamak," Dactoral Disgertation, Princeton UnIversity (January, 1981) 204 PP.

[11] P. Blanc, P. Brouquet, N. Uhre, "Soft X-ray Spectronetry at High ount Rates," EUR-CEA-FC-962, (June 1978) 17 pp.

[12] Equipe TFR, Nucl. Fusion 17, 213 (1977).

[13] G.R. Dyer, G.H. Nel1son, G.G. Kel1y, Nucl. Ingt. Meth. 161, 365 (1979). 
[14] S. von Goeler, พ. Stodiek, H. Eubank, Y. Sun, P. Thompson, S. Slusky, "The X-ray Pulse Helght Analysig Sygtem of the ST Tokamak," MaTT-1060 (1974) $15 \mathrm{pp}$

[15] R.D. Gill, K. B. Axon, J.W.M. Paul, R. Prentice, Nucl. Fusion 19, 1003 (1979).

[16] N.J. Peacock, D.D. Burgess, "New Developments in Measurement Techniques for High Temperature Plagmas," CLY-P612 (April, 1980) 32 pp.

F. Pohl, "X-ray Pulse Height Analys1s," IPP 6/193 (February, 1980) $105 \mathrm{pp}$.

[18] R. Bartiromo, A. Tuccillo, "X-ray Spectroscopic Measurements on FT Tokamak," AgBoclazione EURATOM-CNEN sulla Fusione Centro di Frascati, Report $80.24 / \mathrm{p}$ (June 1980) $19 \mathrm{pp}$.

P. Platz, J. Ramette, E. Belin, C. Bonnelle, A. Gabriel, "High Throughput, High Resolution Soft X-ray Cryetal Spectrometer for Tokamak-Plasma studies," EUR-CEA-FC-1057 (1980) $20 \mathrm{pp.}$

[20] R. Bart1romo, F. De Marco, R. Glannella, s. Mantovan1, G. Pizzicarol1, "nroposal of an $\mathrm{x}-\mathrm{ray}$ Spectrometer for Ion-Temperature Measurements in JET," Associazione .URATOM-CNEN sulla Fusione, Dentro di Frascat1, Report 80.31 (July 1980) $31 \mathrm{pp}$.

[21] K.W. H111, S. von Goeler, M. Bltter, L. Campbell, R.D. Cowan, B. Fraenkel, A. Greenberger, R. Horton, J. Hovey, W. Roney, N.R. Sauthoff, W. Stodiek, Phys. Rev. A19, 1770 (1979).

[22] M. Bitter, S. von Goeler, R. Horton, M. Goldman, K.W. Hill, N. Sauthoff, W. Stodiek, Phys. Rev. Lett. 42, 304 (1979).

[23] N.R. Sauthoff, "The Analygis of Magnetohydrodynemic Modes in Tokamaks by X-ray Techntques," SPIE Vol, 106, x-ray Imag1ng, 40 (1977).

[24] N.R. Sauthoff, S. von Goeler, พ. Stodiek, Nucl. Fusion 18, 1445 (1978). 
[25] D. R. Eames, S. von Goeler, N.R. Sauthoff, W. Stod1ek, "Observations of Several Disruptions in PLT Using Soft and Ultra-Soft X-ray Radiation," PPPL-1530 (March 1979) 52 pp.

[26] G. L. Jahne, M. Soler, B.V. Waddell, J.D. Callen, H.R. Hicks, Nucl. Fugion 18, 609 (1978).

[27] G.I. Jahns, "Observation of Tokamak Plasmas with An Array of PIN Diode Detectors," SPIE Vol. 106, X-ray Imaging, 36 (1977).

[28] M. Bitter, S. von Goeler, N. Sauthoff, K.W. Hill, K. Rrau, D. Eames, M. Goldman, E. Stlver, w. Stodiek, "X-ray Radiation from Tol.amaks," in Proceedings of the International conference on $x-r a y$ Processes and Inner-Shell Ionization, stirling University, Scotland, 1980 (to be publ1shed).

[29] J.A. R. Samson, Technlques of Vacuun Ultravlolet Spectroscopy, (John wiley and Sons, New York, 1967).

[30] E.H. Silver, M. Bitter, K. Brau, D. Eames, A, Greenberger, K. H. Hi11, D.M. Meade, W. Roney, N.R. Sauthoff, S. von Goeler, "Initlal Soft X-ray Measurements from the PDX Tokamak," PPPL Preprint, submitted to Nucl Fusion.

[31] G.A. Doschek, 0. Feldman, R.D. Cowan, "k1gh Regolution X-ray Spectra of Solar Flares v. Interpretation of Innershell Transittons in Fexx-Fe XXIII," NRL Preprint (1980) 48 pp.

H.J. Kunze, "On the Density Dependence of the Intensity Ratio of Resonance and Intercombination Transitions in $c v, "$ Department of Physics and Astronomy, Univeraity of Maryland, Preprint 81-146. S. Suckewer, E. Hinnov, D. Hwang, J. Schivell, G.L. Schmidt, R. Bol, N. Bretz, P. Colestock, D. Dimock, H. Eubank, R. Goldston, R.J. Hawryluk, J. Hosea, H. Hsuan, Z. Meservey, D. McNe111, "Radiation Losges in PLT 
During Neutral beam and ICRF Heating Exper1ments," PPPL-1768 (February 1981) $34 \mathrm{PP}$.

[33] E. Hinnov, R. Bol, D. Dimock, R.J. Hawryluk, D. Johnion, M. Mattiol1, E. Meservey, 5, yon Goeler, Nucl. Fusion 18, 1305 (1978).

[34] S. Kasal, A. Funahash1, M. Nagaml, T. Sugle, Nucl. Fusion 19, 195 (1979).

[35] M. Sh1ho, 5. Konoshima, A. Funahash1, S. Kasa1, T. Sugie, N. Suzuk1, M. Shimada, N. Fujisawa, Nucl. Fusion, 18, 1705 (:978).

[36] K. Brau, S. von Goeler, M. Bitter, R.D. Cowan, D. Eames, K.W. Hi11, N. Sauthoff, E. Sllver, W. Stodiek, nobservations of Glant Recombination Edges on PLT Tokanak Induced by Particle Transport," PPPL-1644 (March 1980) 27 Pp; Phys. Rev. A22, 2769 (1980).

[37] M. B1tter, K.W. H111, N. Sauthoff, P. Efthimion, E. Meservey, W. Roney, S. von Goeler, - .orton, M. Goldman, w. Stodlek, Phys. Rev. Lett. 43 $129(1979)$

[38] See Reference 10 .

[39] TFR Group, Phys. Lett. 74A, 57 (1979).

(40] J.L. Schwob, M. Klaptsch, M. Finkenthal, N. Schweitzer, C. Breton, C. DeMichel1s, M. Matt1ol1, Phys. Lett. 62A, 85 (1977).

[41] R. Engleman, Jr., D.B. Thomson, D.A. Monaghan, Los Alamos Scientific Laboratory Report LA-6275-MS (1976) .

[42] M. Klapisch, J.L. Schwob, M. Finkenthal, B.S. Fraenkel, S. Egert, A. Bar-Shalom, C. Breton, C. DeMici:el1a, M. Mattioli, "Identification of Forbidden Lines in the soft $x$-ray spectrum of the TFR Tokamak," EURCEA-FC-945 (1978) 16 PP.

[43] L.A. Jones, E. Xallnt, D.B. Thomson, J Phys. B Atom. Molec. Phy5. 10 , $187(1977)$. 
[44] A. Pospleszczyk Astron. and Astrophys. 39, 357 (1975).

[45] R.U. Datla, I.A. Jones, D.B. Thomson, "Temperature Diagnostics Using Lithium-Like Sateliftes," Los Alamos Sclentiflc Laboratory Report LA8324-MS (1980) $12 \mathrm{pp}$.

[46] R.L. Brooks, R.U. Datla, H.R. Griem, Phys. Pev. Lett. 41107 (1978).

[47] C. Breton, C. DeMlchelis, M. Finkenthal, M. Mattioli, Phys. Rer, Lett. 41, $110(1978)$.

[48] E. Hinnov, J. Nucl. Materials, 53, 9 (1975).

[19] D.L. Dimock, H.P. Eubank, E. Hinnov, L.C. Johnson, E.B. Meservey, Nucl. Fusion 13, 271 (1973).

[50] D. Meade et al., "PDX Experimental Results," pppL-1740 (1981) 30 pp.

[51] H.P. Furth, Nucl. Fusion 15, 487 (1975).

[52] H.P. Furth, "U.S. Tokamak Research," PPPL-1598 (1979) 11 Pp.

[53) D. Steiner, "Nuclear Fusion: Focus in Tokamak," IEEE Spectrum (July 1977) $32-38$.

[54] J.T. Hogan, "General principles of Magnetic r'ugion Conflnement," ORNL/TN-7107 (1980) 32 PP.

[55] L.A. Artsimovich, Nucl. Fusion 12, 215 (1972).

[56] K.M. Young. "Dlagncstlc Problems of Large Tokanaks," PPPL-1365 (1977) 25 pp, (1n Proc. 5th Int. Conf. on Atomic Physicg, Berkeley, 1976) 391 (Plenum Press, New York, 1977).

[57] J.D. Lawson, Proc. Roy. Soc. (London) B70, 6 (1957).

[58] K. Bol et al.. "Radiarion, Impurity Effects, Instability Characteristics, and Transport in Ohmically Heated Plasma in the PLT Tokamak," PPPL-1492 (December 1978) 25 pp; Plasma Physics and Controlled Nuclear Fusion Research (Proc. 7th Int. Conf. Innsbruck, 1978) 1, IAEA (1979) 11. 
[59] H. Eubank et al., "PLT Neutral Beam Heating Results," FPPL-1491 (November 1978) 47 ppi Plampa Physics and Controlled Nuclear Fusion Research (Proc. 7th Int. Conf. Innsbruck, 1978) 1, IAEA (1979) 197.

[60] J.C. Hosea, "Regimes of Operation in the Princeton Large Torus," PPPL1589 (1979) $11 \mathrm{pp}$.

[61] G.H. Neilson, J.F. Lyon, M. Murakam1, "Injectlon-Dominated Tokamak Experiments at ORNL," ORNL/TM-6506 (1978) 11 Pp.

[62] R.C. Isler, E.C. Crume, H.C. Howe, "Impurity Behavior During Neutral Buam Injection and Gas Puffing into ORMAK," ORNL/TM-6366 (1978) 47 PP; and Nucl. Fusion 15, 727 (1979).

[63] R.C. Isler, Phys. Rev. Lett. 38, 1359 (1977).

[64] J. Hosea et al., "Fagt Wave Heating in the Princeton Large Torus," Preserted at the Course and Workshop on Physics of Plasmas Close to Thermonuclear Conditione, Varenna, Italy (August 1979) 14 pp.

[65] E. Hinnov, "Spectroscopy of Highly Ionized Atoms in the Interior of Tokamak Plasma," in Atoraic and Molecular Processes in Drtrolled Thermonuclear Fusion, edited by M.R.C. McDowell and A.M. Ferendeci (Plenum Publikhing Corp., New York 1980) 449-470.

[66] A major motivation of much of the previously cited development of $x-$ ray diagnostics was impurity studies, i.e., identification, radiative power loss, concentration, charge-state distributions, and transport.

[67] V.V. Afroslmov, Yu. S. Gordeev, A.N. Zinov'ev, A.A. Rorotkov, JETP Lett. $28,500(1978)$.

[68] F. DeMarco, "Impurity concentration in the ATC," Princeton Report MATT$1012(1973) 9$ pp.

[69] E. Hinnov, L.C. Johnson, E.B. Meservey, D.L. Dimock, Plasma Physics, 14. 755 (1971). 
[70] E. Hinnov, Phys. Rey. A14, $1533(1976)$.

[71] E. Meservey, N. Bretz, D. Dimock, E. Hinnov, "Suppression of Heavy Imjurities in the ST Tokamak," MATT-1175 (1975) 3 pp.

[72] S. Suckewer, J. cecchi, S. Cohen, R. Fonck, E. Hinnov, "Tracer Element Injection Into PDX Tokamak for Spectral Line Identification and Locallzed Doppier Temperature Measurement," PPPL-1712 (1980) 9 pp.

[73] E. Hinnov, M. Mattioli, "Observations of Multiply Ionized Tungsten Padiation in the PIT Discharges," PPPL-1375 (1977) 9 pP.

[74] S. Sickewer, E. Hinnov, "Iron Forbidden Linea in Tokamak Discharges," PPPL- 1524 (1979) $26 \mathrm{pp}$.

[75] S. Suckewer, R. Fonck, E. Hinnov, "Observed Magnet1c Dipole Iransit1ons in the Ground Terms of Ti XIV, Ti XV, and Ti XVII," PPPL-1591(1979) 10 pp.

[76] S. von Goeler, D. Eames, M. Bitter, X.w. Hill, G. Lenner, N. Sauthoff, E. Silver, W. Stodiek, "Iron and oxygen Radiation in the Ultrasoft $X-$ ray Region (USX) from PLT," Baton Rouge, LA (1981), see Ref. 130.

[77] S. Suckewer, E. Hinnov, K. Bol, R. Fonck, R.3. Hawryluk, R.A. Jacobsen, D.M. Meade, M. Okabayashi, G.L. Schmidt, E.H. Silver, J.C. Sinnis, "Titanium Density Measurements in the POX Tokamak Using Ti XVII Forbidden Line," PPPL-1563 (1979) 12 pp.

[78] W. Stodiek et al., "Traroport Studies in the Princeton Large Torus," Plasma Physics and controlled Nuclear Fusion Research (Proc. 8th Int. Conf. Brussels, 1980) to be published.

[79] R.C. Isler, E.C. Crume, Phys. Rev. Lett. 41, 1296 (1978).

[80] R.C. Isler, R.V, Neldigh, R.D. Cowan, Phys. Lett. 63A, 295 (197).

[81] E.S. Warden, H.W. Moos, N.H. Lazar, "Observations of Low Charge State Impurities in EBT," ORNL/TM-5899 (1977) is pp. 
[82] J.E. Rlce, E.S. Marmar, T. Coan, S.L. Allen, R.D. Cowan, Phys, Rev. A22, $310(1980)$

[B3] J.L. Terry, K.I. Chen, H.W. Moog, E.S. Marmar, Nucl. Fuglon 18, 485 (1978).

(84) K.I. Gen, J.L. Terry, H.W. Moos, E.S. Maremar, Nucl. Fuston 20, 189 $(1980)$

[B5] E.S. Marmar, D. Overskel, H. Helava, K.I. Chen, J.L. Terry, H.R. Moos, Nucl. Fusion 19, 485 (1979).

!86! S.L. Illen, H.H. Mos, R.K. Rlchardz, J.L. Terry, E.S. Marmar, Nucl. Fuston $21,251(1981)$.

[B]! C. Beton, C. Desichel:, M. Mattiol1, Nuc1. Fusion 16, B9? (1976).

(88) Equipe TFR, Nucl. Fus1on 15, 1053 (1975)..

!89: R.P. Drake, H.W. Moos, Nucl. Pusion 20, 599 (1980).

[90] TFR Group, "Are heavy Impurities in Tokamak Plasmas at Ionization Equilibriun?", EUR-CEA-PC-1033 (1980) $23 \mathrm{pp}$.

[91] TFR Group, Phys. Rev. Lett. 36, 1306 (1976).

[92] C. Breton, C. DeMichelis, M. Mattioll, "Spectroscopic Study of Ohmlcally Heated Tokamak D1scharges," EUR-CEA-FC-1060 (9980) 42 pp.

[93] M. Naganl, Y. Shimorura, H. Maeda, S. Kaba1, T. Yamiuch1, S. Sengoku, T. Sugie, S. Yamamoto, K. Odajlma, H. Kimura, K. Ohasa, Nucl. Fusion $18,1347(1978)$.

994) K. Odajima, H. Maeda, M. Shiho, H. Ximura, S. Yamamoto, M. Nagami, S. Sengoku, T. Sugle, S. Kasai, M. Azuml, Y. Shlmomura, Nucl. Fusion 18, $1337(1978)$

[95] R. Paul Drake, Extreme Ultraviolet Díagnosis of a Neutral-Bean-Heated M1rror Machine," UCRL-52751 (1980) 169 pp. 
[96] N.H. Lazar, K.H. Carpenter, J.M. Tyson, E.S. Warden, H.W. Moog, Nucl. Fusion 19. $571(1979)$. S. Sesnic, "Evolution of Internal Modes, Disruptions, and High-Z Impuritieg at High Density in Pulsator," IPP III/22 (1976) 83 pP.

[98] G.M. McCracken, P.E. Stott, Nucl. Fusion 19, 889 (1979).

[99] K.H. Burrell, J.C. DeBoo, E.S. Ensberg, R. Prater, S.K. Wong, C.E. Bush, R.J. Dlchln, P.H. Edmonds, K.W. Hill, R.C. Isler, T.C. Jernigan, M. Murakami, G.H. Nellson, Phys. Rev. Lett. 41, 1382 (1978).

[100] R.J. Colchin, et al., "Plasma-Wall Impurtty Experiments in ISX-A," ORNL/TM-6446 (1978) $13 \mathrm{pp}$.

[101] K.H. Burrel1, Phys. Fluids 19, 401 (1976).

(102) P. Gratreau, "Numerical simulation of the Diffusion and Ionization Processes for Highly Ionized Impurities In Tokamak Discharges, With Application to Confinement Time Determination," CNEN Edizioni Scientifiche Report $79.10 / \mathrm{p}$ (1979) $39 \mathrm{pp}$.

[103] D.M. Meade, Nucl. Fuston 14, 289 (1974).

[104] A.J. Hawryluk, J.A. Schmidt, Nucl. Fusion 16, 775 (1976).

[105] P.H. Rutherford, S.P. Hirshman, R. Jensen, D.E. Post, F.G.P. Seidl, "Impurity Transport in Tokimaks," PPPL-1297 (1976) 19 pp.

[106] R.V. Jensen, D.L. Jassbr, D.E. Post, "Crltical Impurity Concentratlons for Ignition of Catalyze.1-Deuterium Fusion Plagnas," PPPL-1368 (1977) 9 PP.

[107] R.V. Jensen, D.E. Post, W.H. Grasberger, C.B. Tarter, W.A. Lokke, "Calculation of Impurity Radiation and Its Effects on Tokanak Experiments," PPPL-1334 (1977) 27 pp.

[108] D. Post, "Impurity Radiation Losses in Fusion Plasmas," In Atomic Procesgeg in Fusion Plasmas, Nagoya University Report IPPJ-AK-13 (1979) $38-43$. 
[109] E.J. Caramana, F.H. Perkins, Nucl. Fusion 21, 93 (1981).

[110] D.E. Roberts, Nuc1. Fusion 21, 215 (1981).

[111] T. Amano, E.C. Crume, "Simulation of Multispecies Impurity Transport in Tokamaks," ORNL/TM-6363 (1978) 29 pp.

[112] C. Breton, C. DeMthhelis, M. Mattioli, "Ionization Equilibrium and Radiation Coling of a High Temperature Plasma," EUR-CEA-FC-853 (1976) 25 PP.

[113] C. Breton, C. DeMichelis, M. Finkenthal, M. Mattloli, "Ionization Equilibriun of Selected Elements from Neon to Tungsten of Interest in Tokamak Plagma Regearch," EUR-CEA-FC-949 (1978) 18 pp.

[114] M.E. Puiatti, C. Breton, C. DeMichelis, M. Mattlol1, "Impurity Charge Exchange Processes in Tokamak Plasmas," EUR-CEA-FC-1085 (1981) 35 pp.

[115] D.E.T.F. Ashby, M.H. Hughes, "A study of the Effect of Impurity Radiation from the Peripheral plasma of a Tokamak Reactor," CLM-P625 (1980) $52 \mathrm{pp}$; Nucl. Fusion 20,451 (1980).

[116] C.S. Chang, "Anomalous Impur1ty Transport in a Tokamak with Large Toroidal Plasma Rotation," GA-A16123(1981) 10 Pp.

[117] D.M. Meade, H.P. Furth, P.H. Rutherford, F.G.P. Se1dl, D.F. Düchs, "The Effects of Impurities and Magnetic Divertors on High Temperature Tokamaks," Plasma Physics and Controlled Nuclear Fusion Research (Proc. 5th Int. Conf. Tokyo, 1974) 1, IAEA (1975) 605.

[118] A.L. Merts, R.D. Cowan, N.H. Magee, "The Calculated Power Output from a Th1n Iron-seeded Plagma," LASL Rep. LA-6220-MS (1976).

[119] E.B. Meservey et al., "The Effect of Plasma Surface Interactions on PLT Plasma Parameters," PPPL-1677 (1980) 14 pp.

[120] "Status of Tokanak Research," edited by J.M. Rawls, DOE/ER-0034 (1979). 
[121] R.D. Cowan, "Spectra of HIghly Ionlzed Atome of Tokariak Interest," LA6679-MS (1977) 81 pp.

[122] D. Hill1g, Oak Ridge National Laboratory, EBT group, private communication.

[123] J.E. Rtce, K. Molvig, H.I. Helava, "Continum X-ray Emission from the Alcator A Tokamak," PFC/JA-81-5 (1981) 75 pp.

[124] TER Group - J. L. Schwcb, "Intercombirstion to Resonance LIne Intensity Ratlo for He-L1ke Oxygen Ions in TFR Tckanak Plasmas," EUR-CEA-FC- 1072 (1980) 15 pp.

[125] K.W. Hill, S. von Goeler, M. Bitter, E. Silver, N.R. Sauthoff, "The Pulse-Height Analyzex $x$-ray Dlagnostlc for TFTR," presented at the Third APS Toplcal Conference on High Temperature Plasma Diagnost1cs, Los Angles, CA, March 17-19, 1980.

[126] F. S. Gouldung, J.M. Jaklevic, A.C. Thompson, "Semicorductor Detectors for Fluorescent Exafs," Proceedings of workshop on $x$-ray Instrumentation for Synchrotron Radiation Research, SSRL Report No. $78 / 04, I I-22(1978)$

[127] G.A. Sawyer, A.J. Bearden, I. Henins, F.C. Jahoda, F.L. Ribe, Phys. Rev. 131, $1891(1936)$.

[128] N. Bretz, D. Dimock, A. Greenberger, E. Hinnov, $\Sigma$, Meservey, W. Stodiek, s. von Goeler, "Radiation From Plasmes in the ST Tokamak," MATT $1077(1974)$ 10 pp.

[129] B.S. Fraenkel, X-ray Spectroscopy 9, 189 (1980).

[130] E. Källne, J. Källne, J.E. Rice, "X-ray Emigsion Spectra From HellumIike Ions In the Alcator C Tokamak," presented at the Third Topical Conference of the APS on Atomtc Processes in High Temperature plasmas, Baton Rouge, LA, Eebruary 25-27, 1981; L.V. Hamos, Zeltschr. F. Krigtallographle $101 \mathrm{Bd} ., 17$ (1938). 
[131] E. Käline, private communication.

[132] S. von Goeler, w. Stodiek, N. Sauthoff, Phys. Rev. Lett. 33,1201 $(1975)$

[133] S. Sesnic, "Evolution of Internal Modes, Digruptions, and High-Z Impuritles at High Density in Pulsator," IPP III/22 (1976) 83 pp.

[134] N.R. Sauthoff, S. von Goeler, D.R. Eames, W. Stodiek, "Successot Oscillations of Internal Digruptlve Instabllities in the PLT Tokamak," PPPL-1553 (1979) 17 Pp.

[135] R. Petrasso, M. Gerassimenko, F.H. Seguln, J. TIng, R. Krogstad, P. Gauthler, W. Hamilton, A.T. Ramsey, P. Bursteln, R. Granetz, Rev. Sci. Instrun. $51.585(1980)$

[136] W VII-A Team, "Mode and Sawtooth Behavior During Neutral Beam Injection Is the W VII-A stellarator," IPP $2 / 250$ (1980) $21 \mathrm{pP}$.

[137] T.F.R. Group, "Structure of Low Frequency Oscillations of the Disruptive Instability in the TFR Tokamak," EUR-CEA-FC-883 (1977) 55 PP.

[1 B] The T.F.R. Group, Plasma Phys. 19, $349(1977)$.

[139] R.B. White, D.A. Monticel1o, "Causes of Major Tokanak Disruptions," $\left.\mathrm{PPi}_{\mathrm{i}}:-1674 \cdot 1980\right) 15 \mathrm{Pp}$.

[140! M. Soler, J.D. Callen, "On Measuring the Electron Heat Diffusion coefficient in a Tokamak from Sawtooth Oscillation observations," ORNL/TM-6165 (1978) 37 pp.

:141! S. von Goeler, D. Eames, M. Bitter, K.w. H1ll, N. Sauthoff, E. Silver, w. Stodiek, Bull. An. Phys. Soc. 25, 998 (1980).

:142) N.D. Vinagradova et al., "Invegtigation of Plasma X-ray Emission in the T-1- Tokamak," In Plasma Physteg and Controlled Nuclear Fuston Research (Proc. 7th Int, Conf, Innsbruck, 1978) 1, IAEA (1979) 257. 
[143] T.T. Hamilton, C.J. Halley, W.H.-M. Ku, R. Novick, IEEE Trans. Nucl. Sci. NS-27, $190(1980)$.

[144] J.E. Bateman, R.J. Apsimon, "A New photocathode for X-ray Image Intensiflers operating in the 1-50 keV Reglon," Rutherford Laboratory, Chilton, UK, Report RL 79-087 (1979).

[145] Private communication, R. Fonck and B. Hodge. 
FIGURE CAPTIONS

Fig. 1 Schematic 1llugtrating principles of tokamak operation. (\#753361)

Fig. 2 Sample electron temperature and density profile from PIT measured by Thomson scattering. (\#809052)

Fig. 3 Fractional abundance of several charge states of Ar vs. electron temperature for coronal equilibrium. (\$783804)

Fig. 4 Comparison of the radiative power loss for a varlety of impurities. (\#772499)

Fig. 5 PHA $X$-ray spectra from four chords of $P D X$ at $r=0,12,16$, and 24 cm. Temperature profiles at several t1mes, deduced from $x$-ray continua, are shown in fnget. (\#793687)

Fig. 6 X-ray spectrum from the EBT device measured by an array of $S i(L i)$ detectors. (Ref. 122).

Fig. 7 schematic of the mult1-detector PHA system installed on PLT. (\$773872).

Fig. B Schematic of the Johann X-ray Crystal Spectrometer used on PLT and PDX. (\$773846) 
F1g. 9 Sample $F e K_{\alpha}$ spectra at different electron temperatures illustrate the shift to higher ionization states as temperature increases. (\#7733660)

F1g. 10 Sample ultra-high resolution Fe $K_{\alpha}$ spectrum from PLT. The resonance line $w$ of Fe XXV at $1.85 \AA$ is uged for Doppler 1on-temperature measurement. (\#793023)

F1g. 11 The Ion Temperature in PDX derived from Doppler broadening of the T1

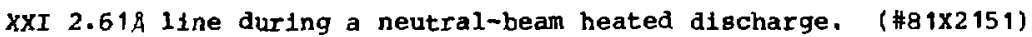

Fig. 12 schematic of X-ray imaging Bystem using an array of silicon ourfacebarrier detectors, as used on PLT. (\$796219)

Fig. 13 X-ray emisgivity vs. time for beveral chords from PDX, ghowing an $m=1$ oscillation. Stars Indicate chord radius and zero level of emissivity. (\#806858)

Fig. 14 Radial profiles of $\mathrm{X}$-ray emissivity vs. time for the m=1 oscillation of Fig. 13. \{\#806833\}

Fig. 15 soft $x$-ray traces vs. time from Imaging system on PLT showing an explosive disruption at $305.2 \mathrm{~ms}$. (\$793050)

Fig. 16 Implosive type of disruption of 514 ms as measured by ultra soft $x-$ ray imaging system on PLT. (\$793049) 
Fig. 17 Schematic of the rotating crygtal spectrometer installed on PLT and photograph of the crystal and detector assembly. (\#B09045)

Fig. 18 Output from rotating crystal spectrometer with 3 different time scales. (a) Timing pulses generated when a slot in the rotating disk passes the LED. (b) MIcrochannel plate output obtained as the crystal rotates. (\$809056)

Fig. 19 Iron L spectrum measured with the rotating crystal spectrometer. $(\$ 806747)$

Fig. 20 oxygen $K$ spectrum from PLT discharge with high oxygen level. (\#809110)

Fig. 21 Chord Integrated intensity profiles of several iinn-I transitions for different charge states, measured by the rotating crystal spectrometer. (\$B06748) 

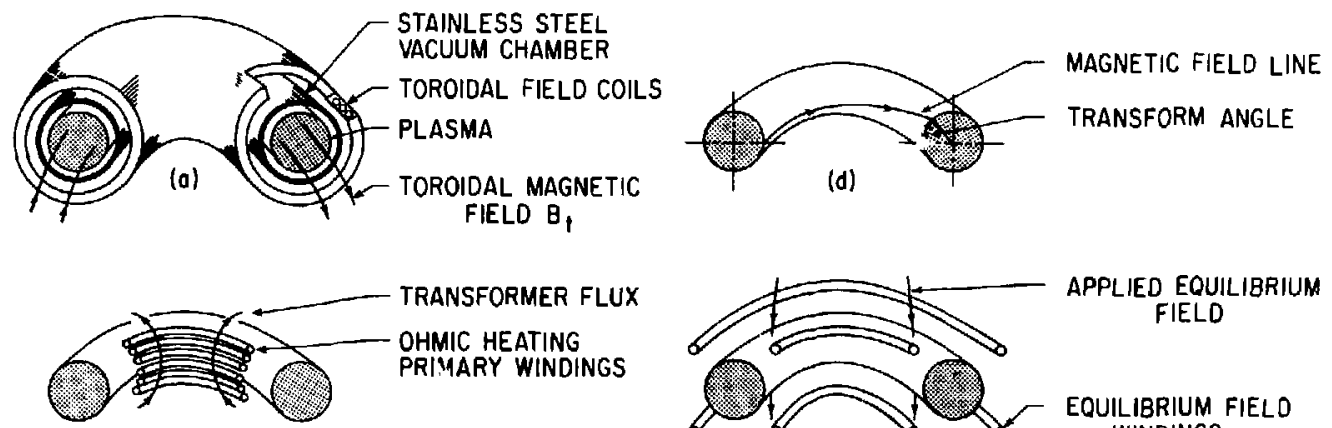

(b)

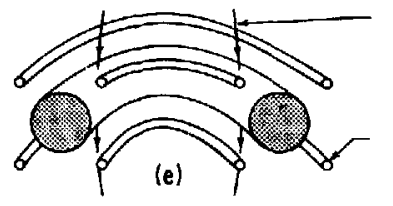

APPLIED EQUILIBRIUM FIELD

EQUILIBRIUM FIELO

WINDINGS
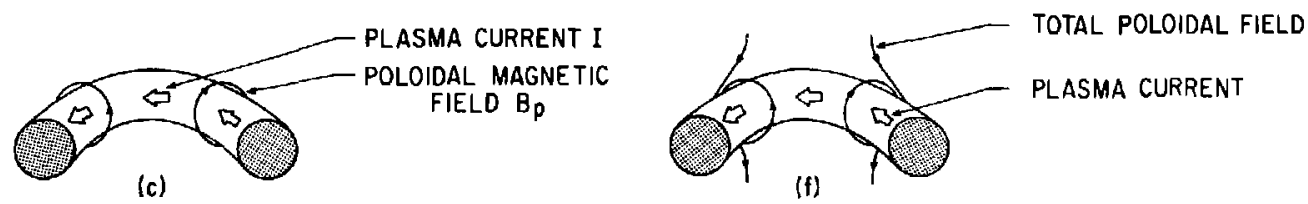

Fig. 1 


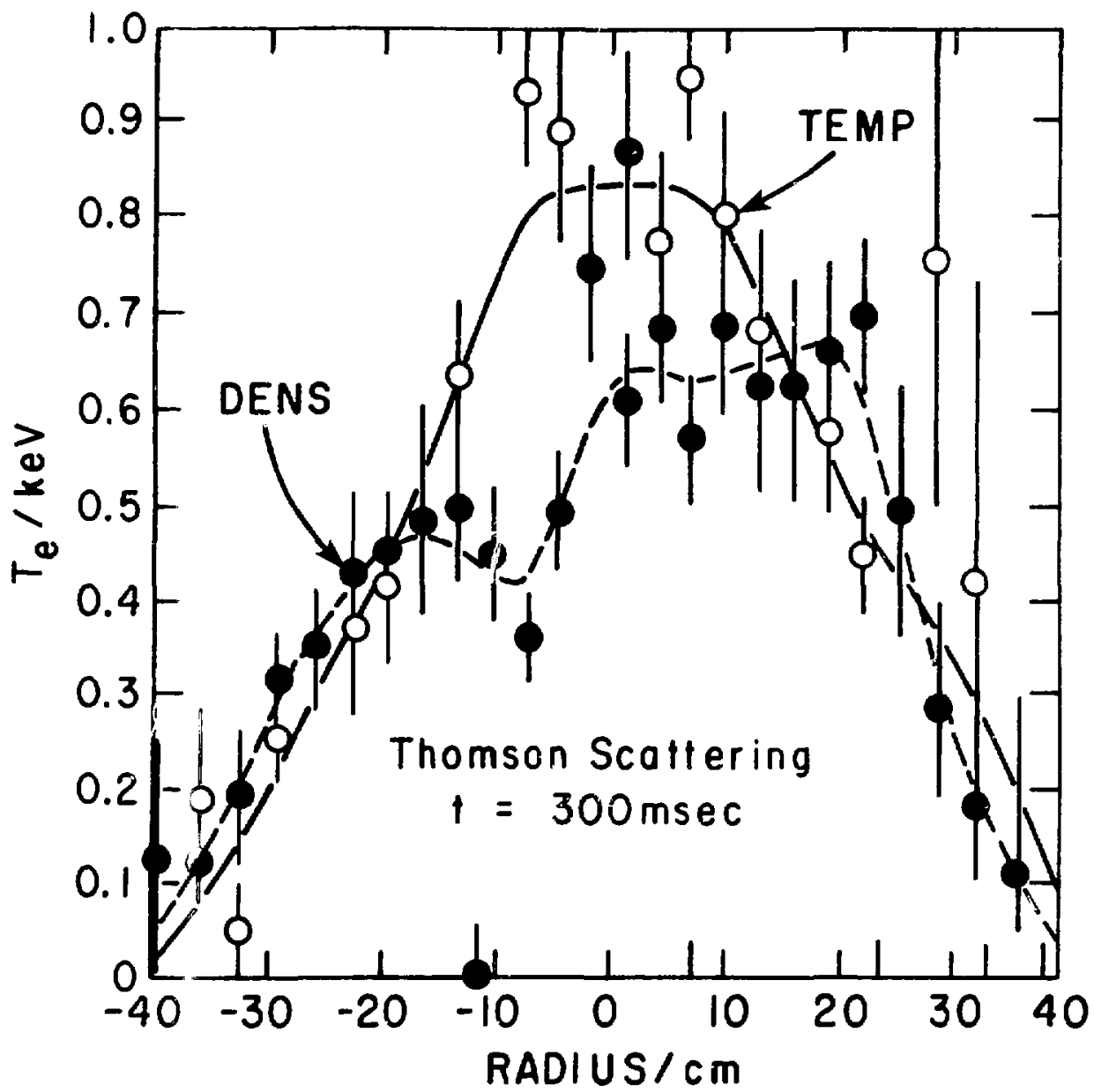

Fig. 2 


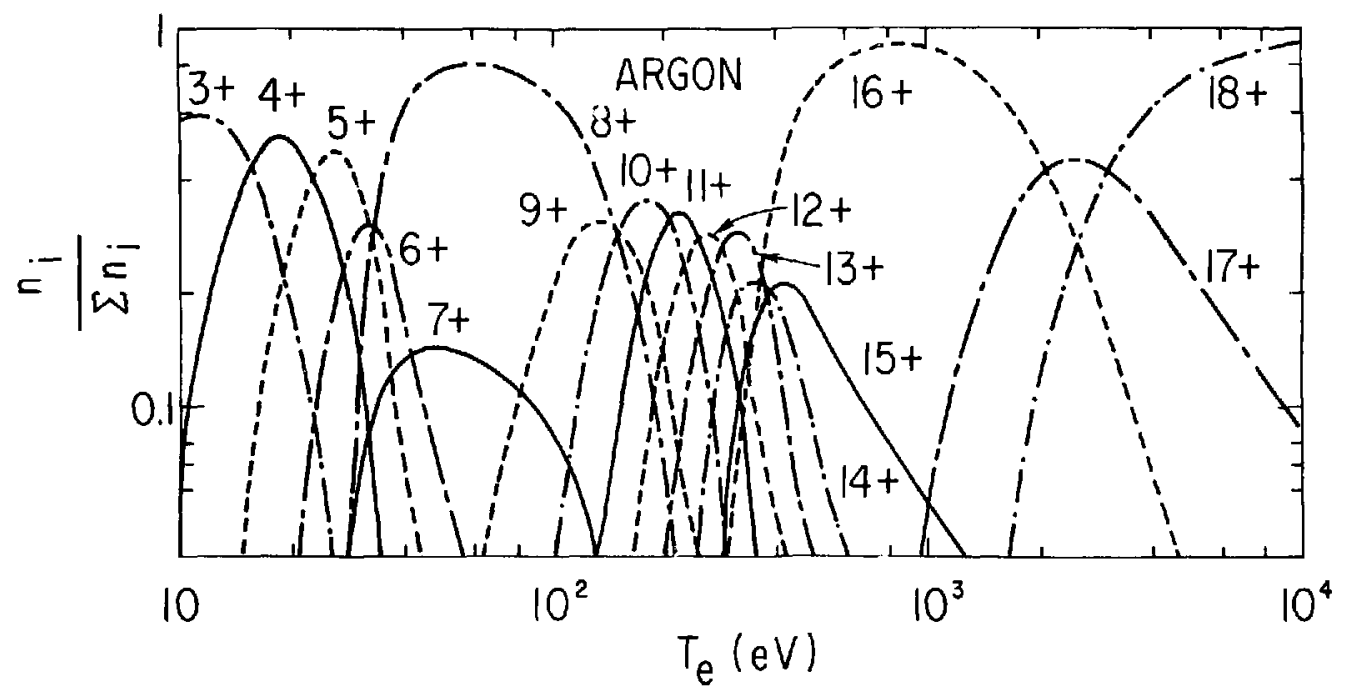




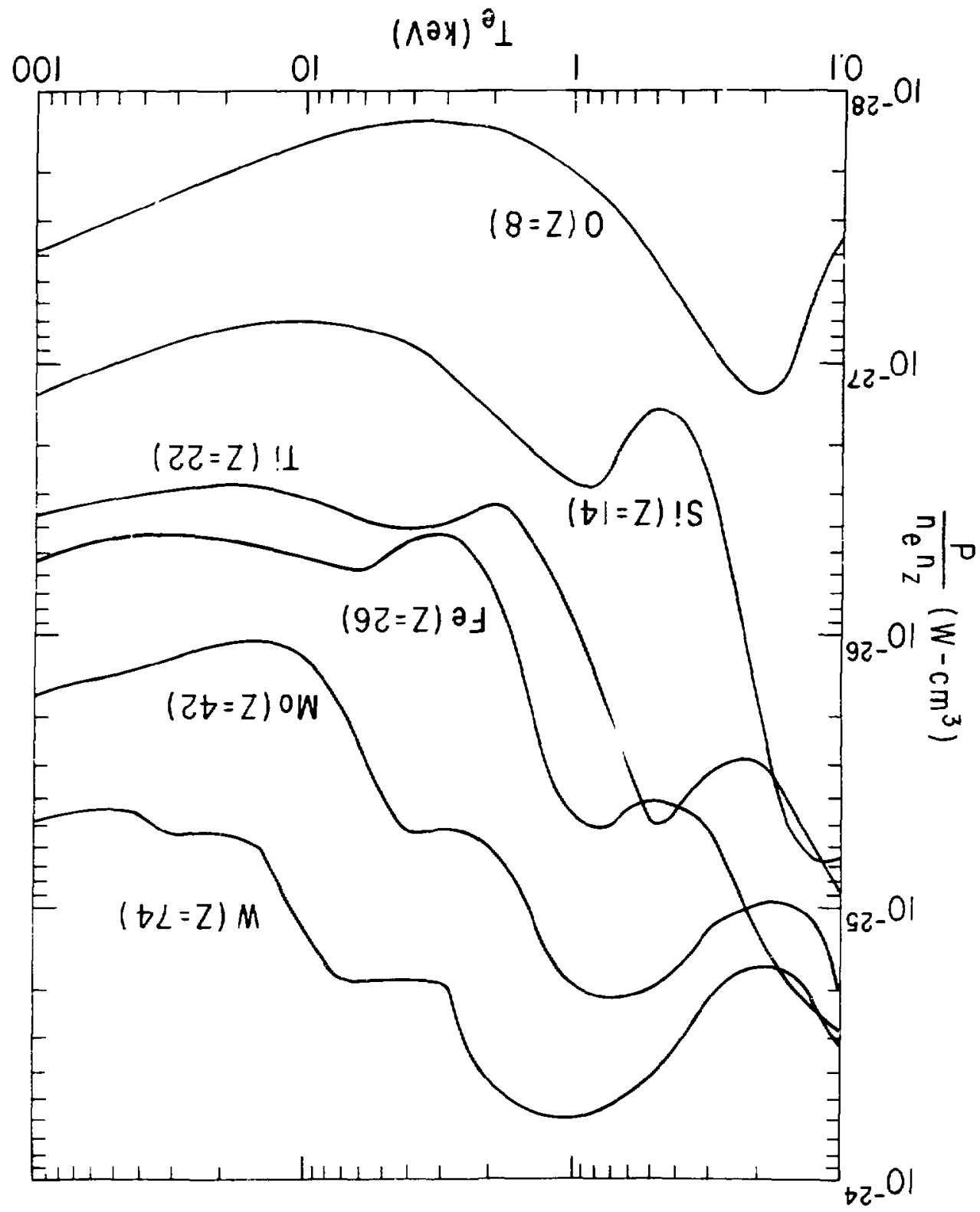




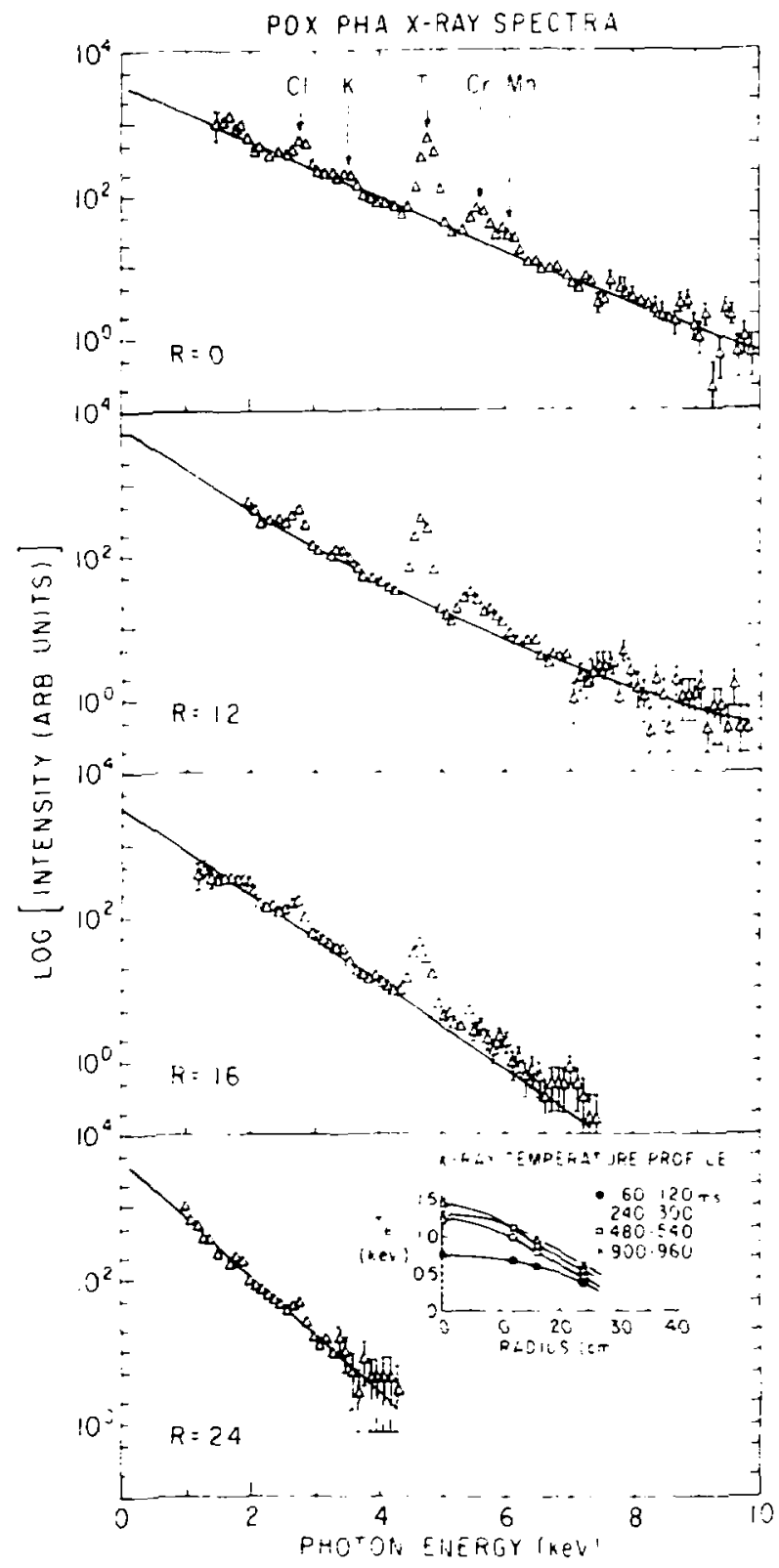

Fig. 5 


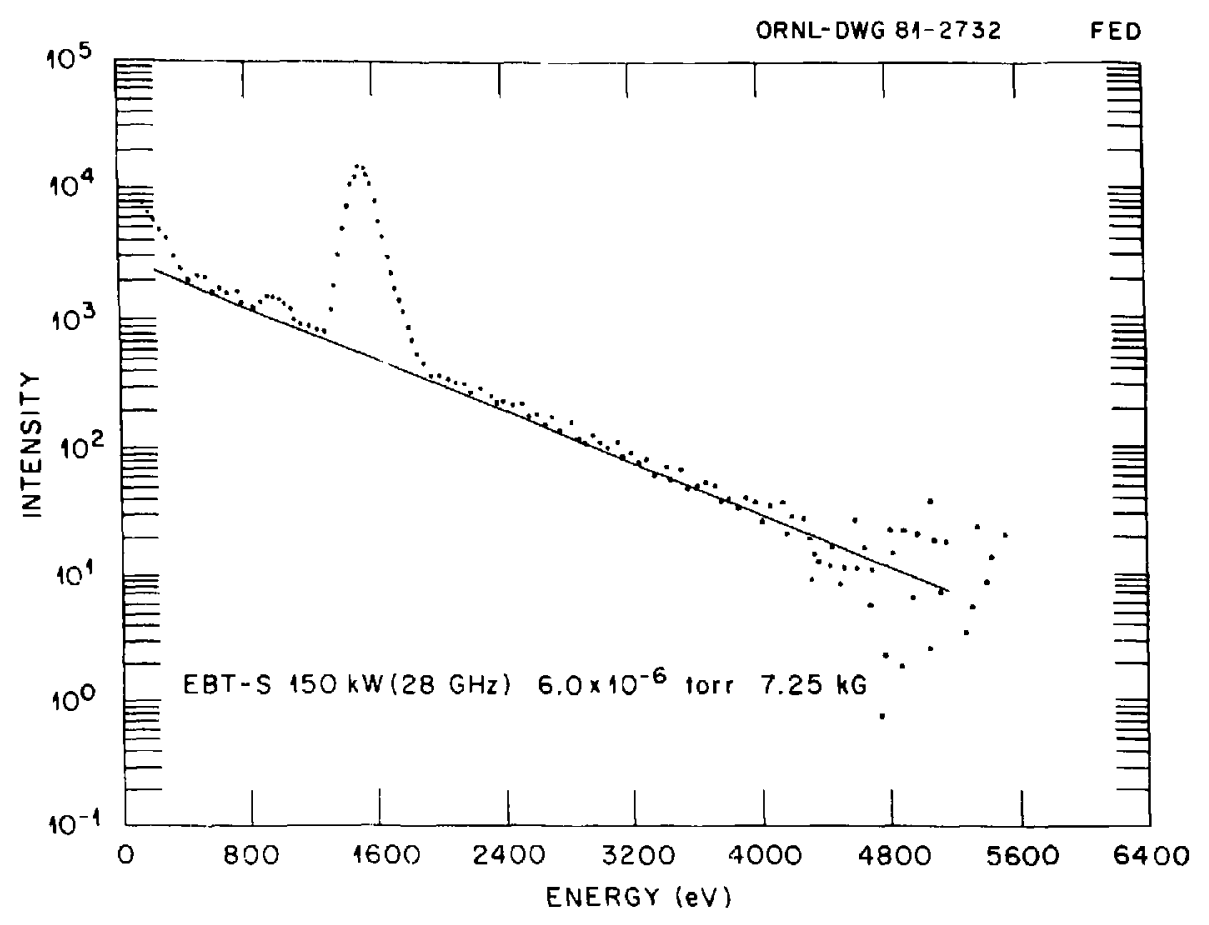




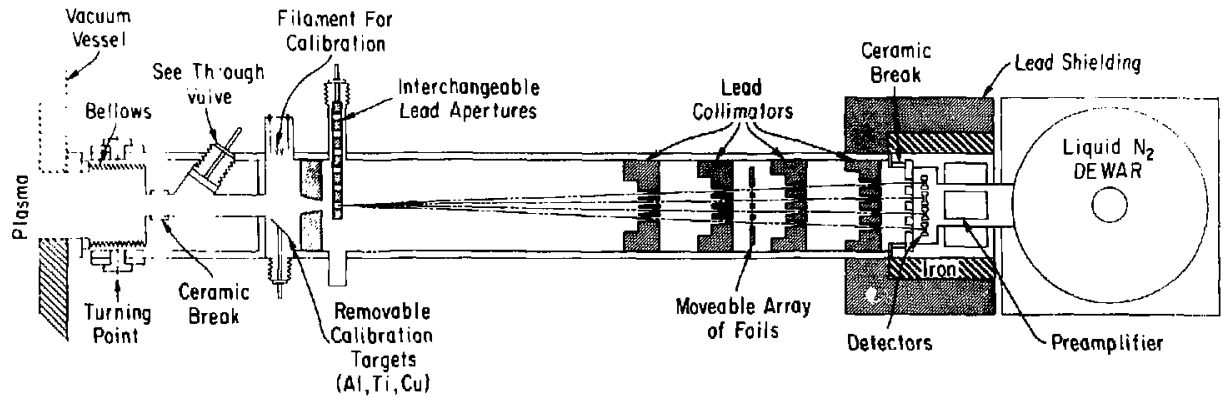

\section{ELECTRONICS}
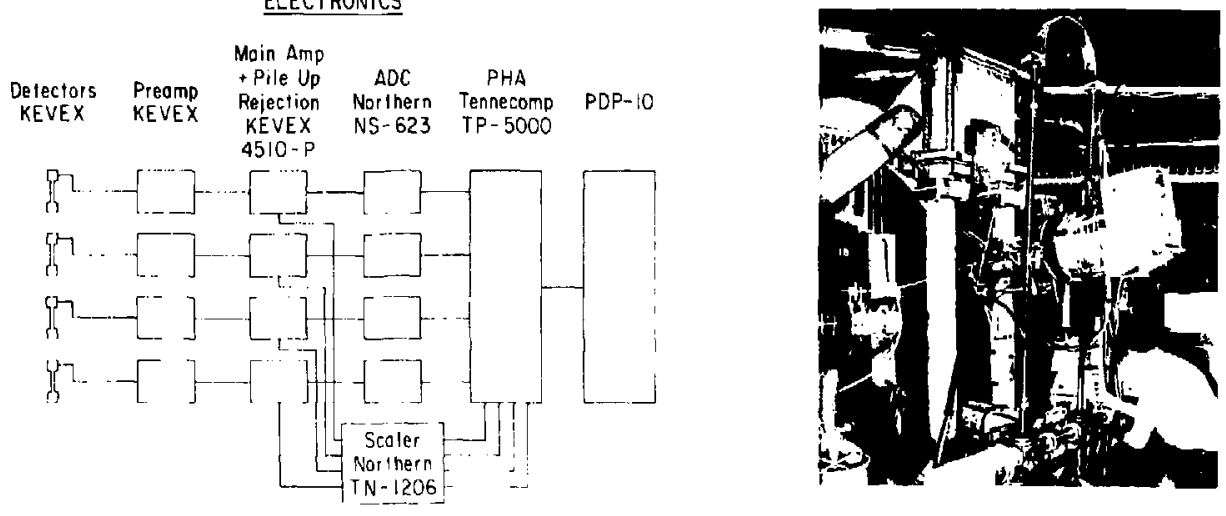
CURVED-CRYSTAL SPECTROMETER

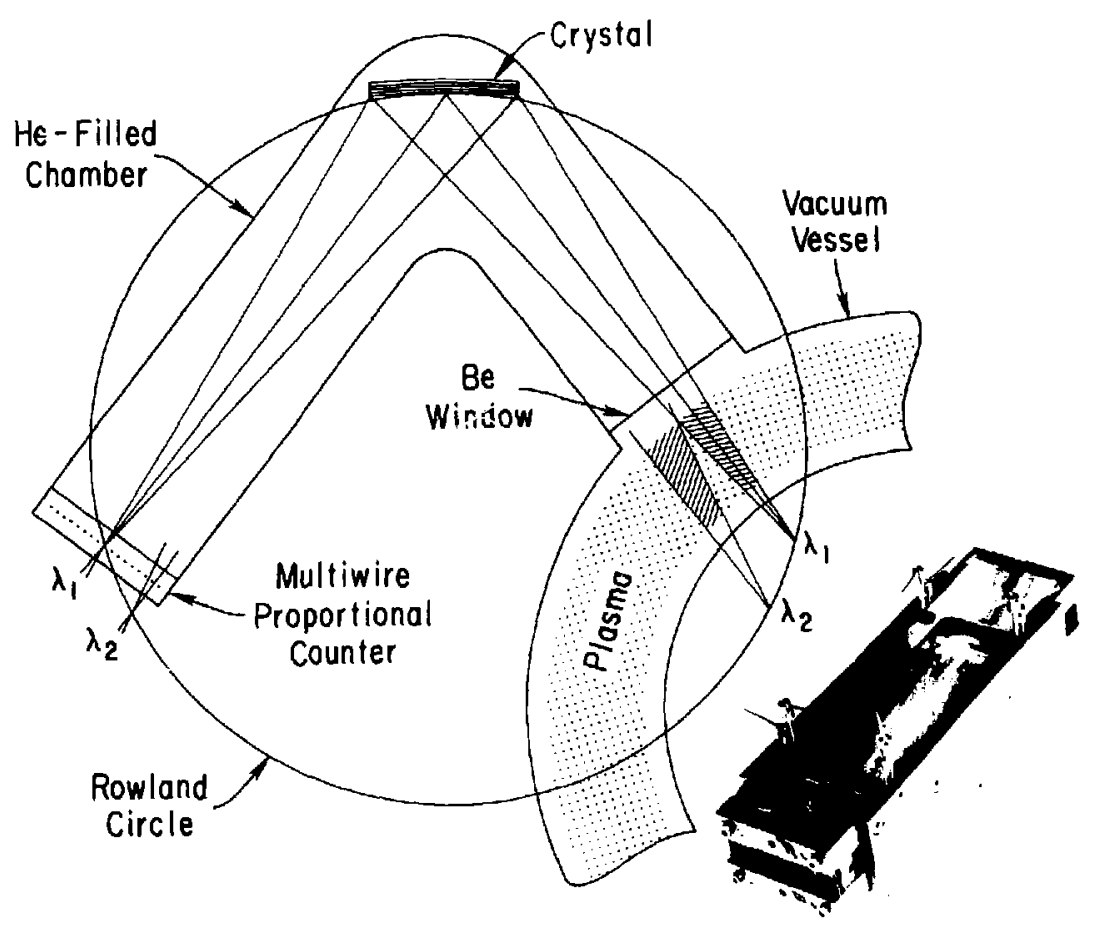




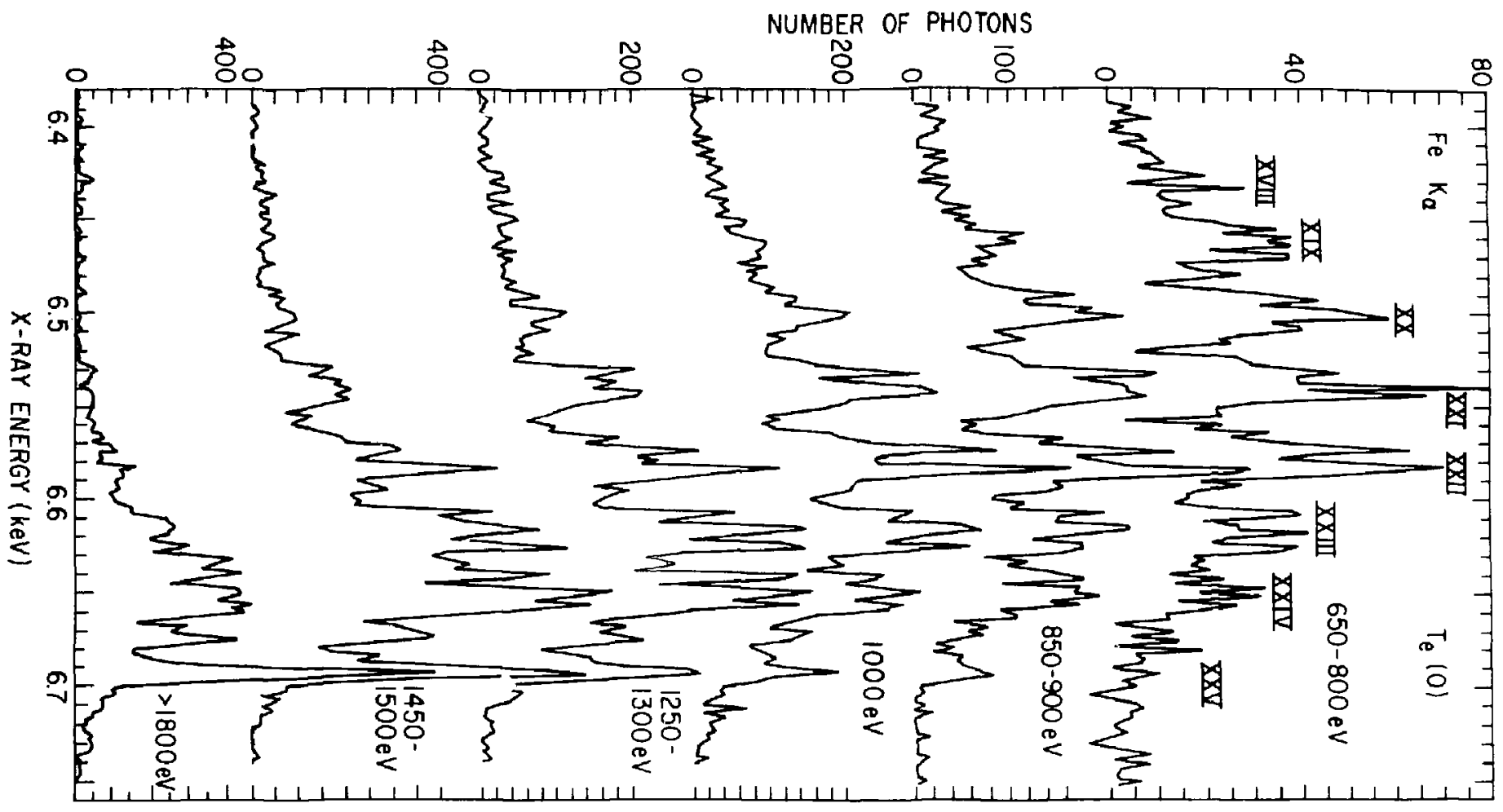




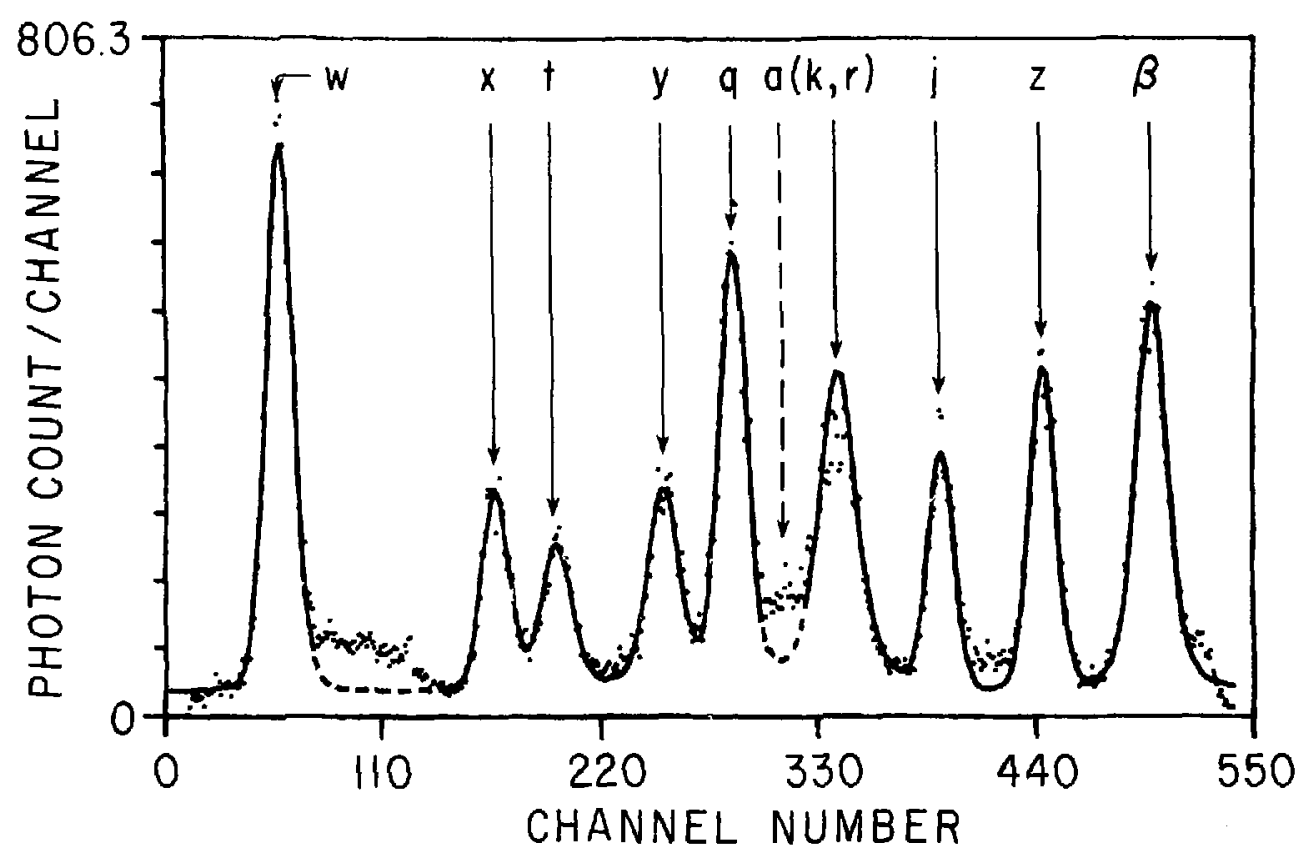




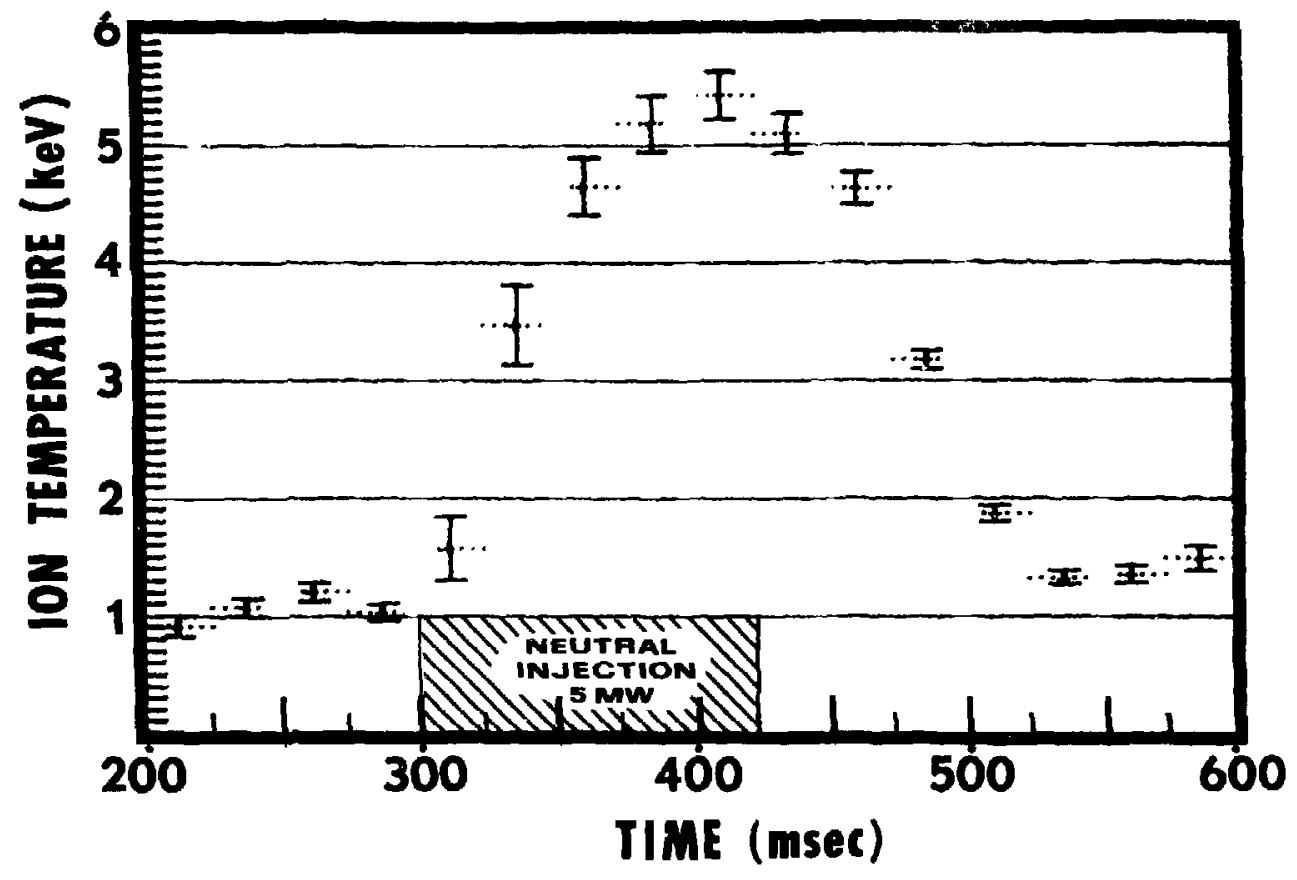




\section{PLT/PDX X-RAY WAVE DETECTOR SYSTEM}

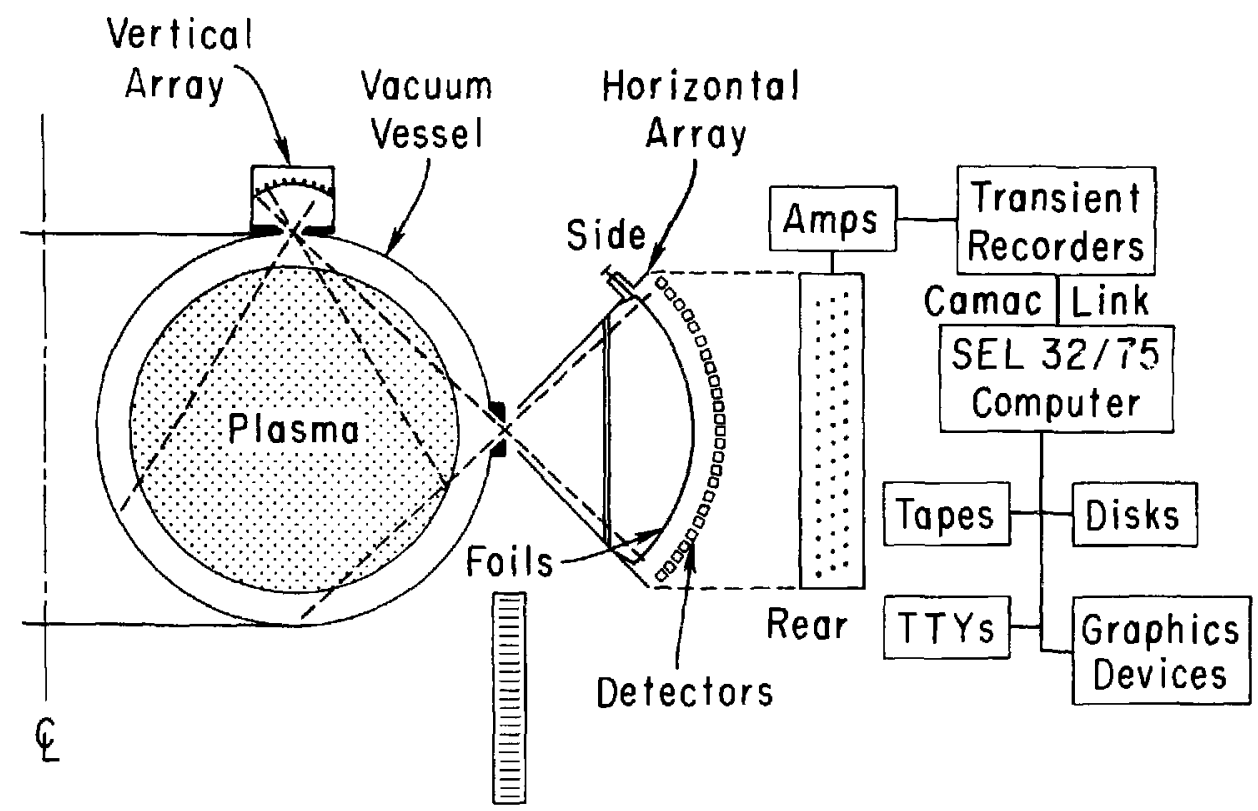




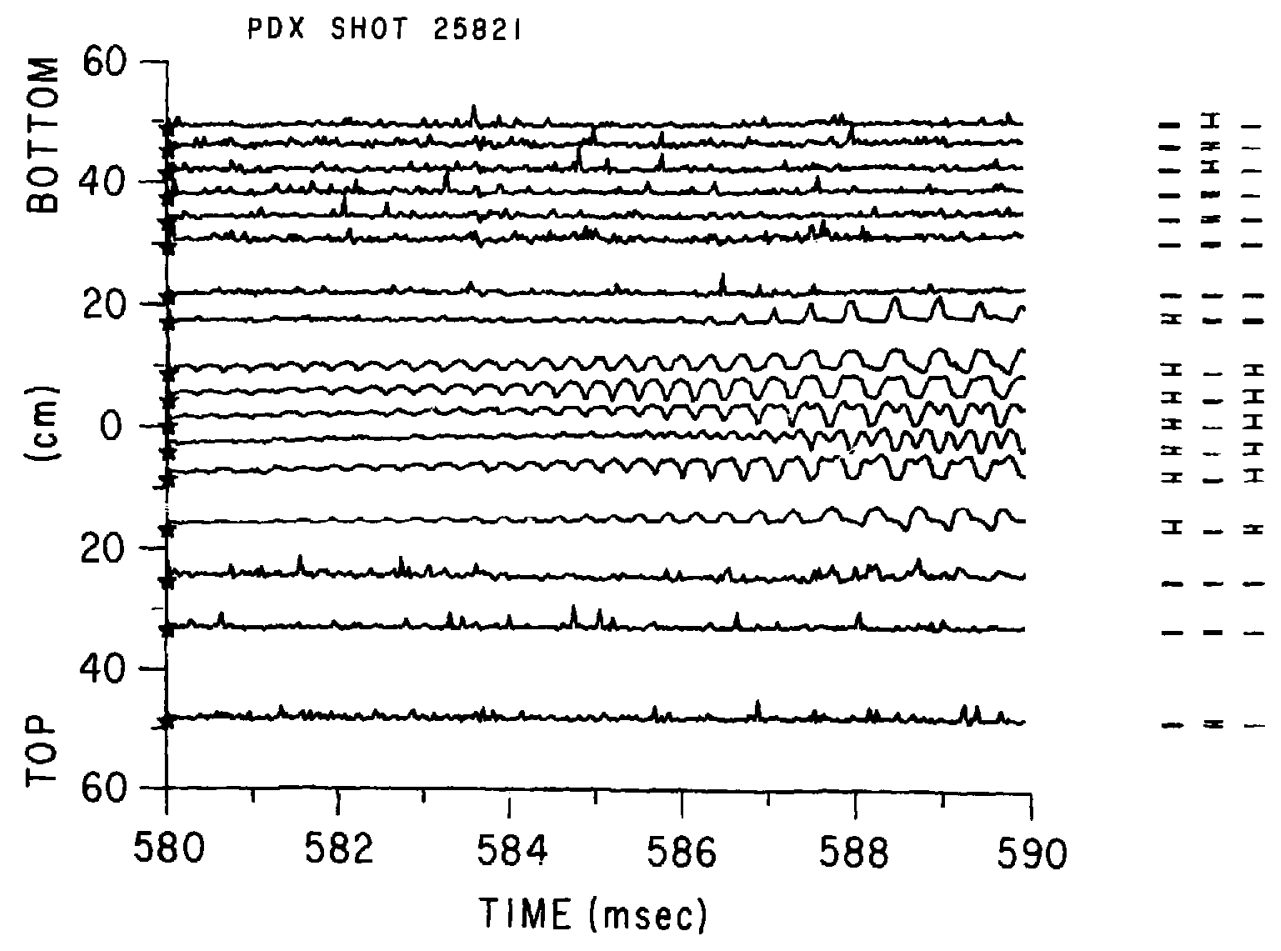




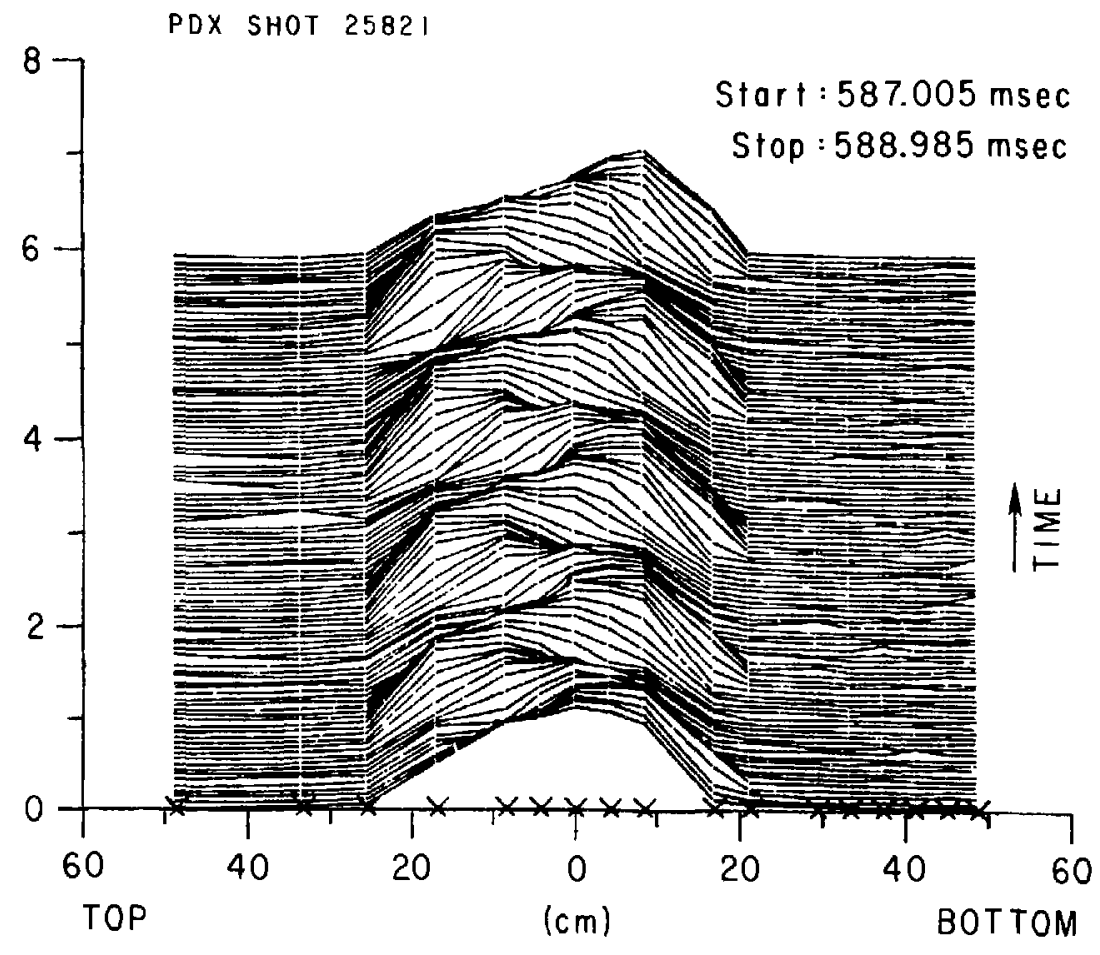




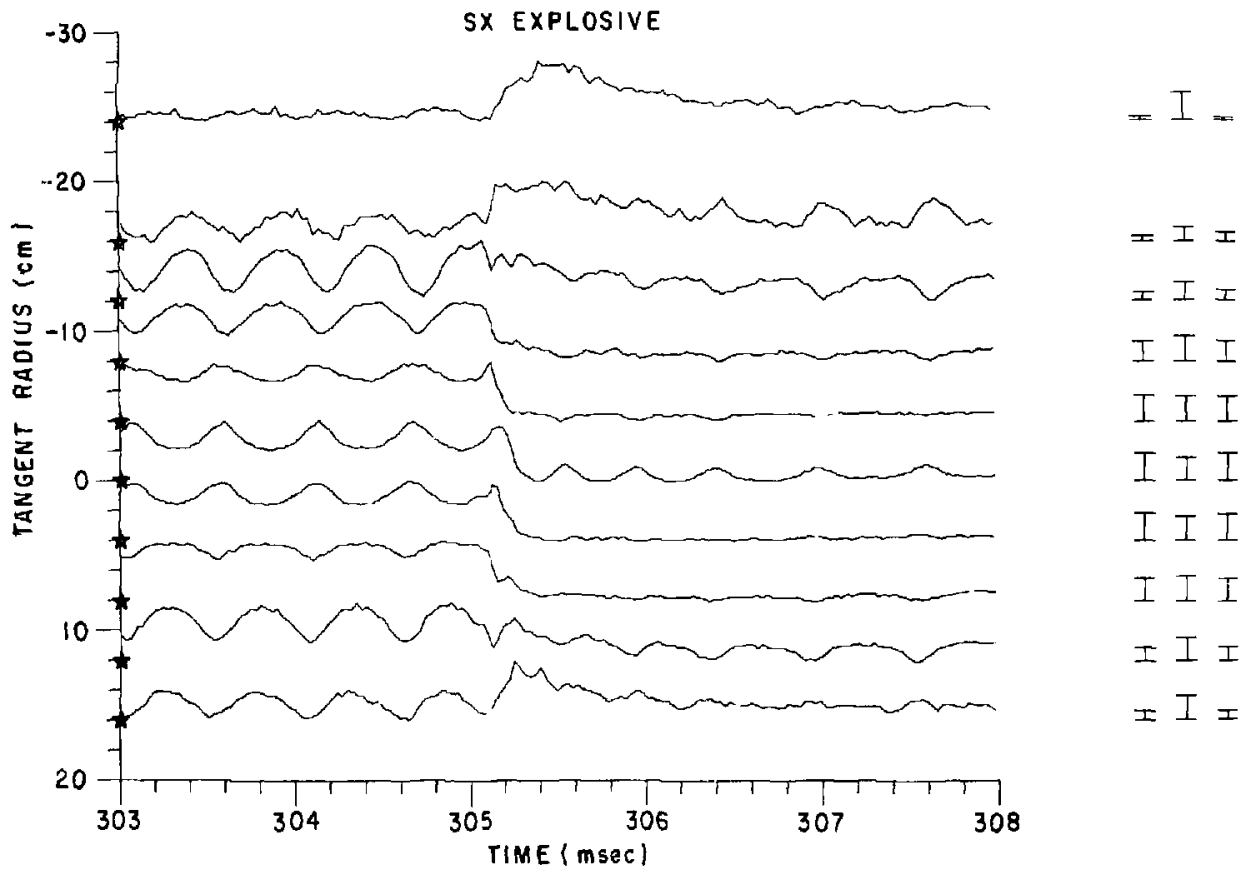




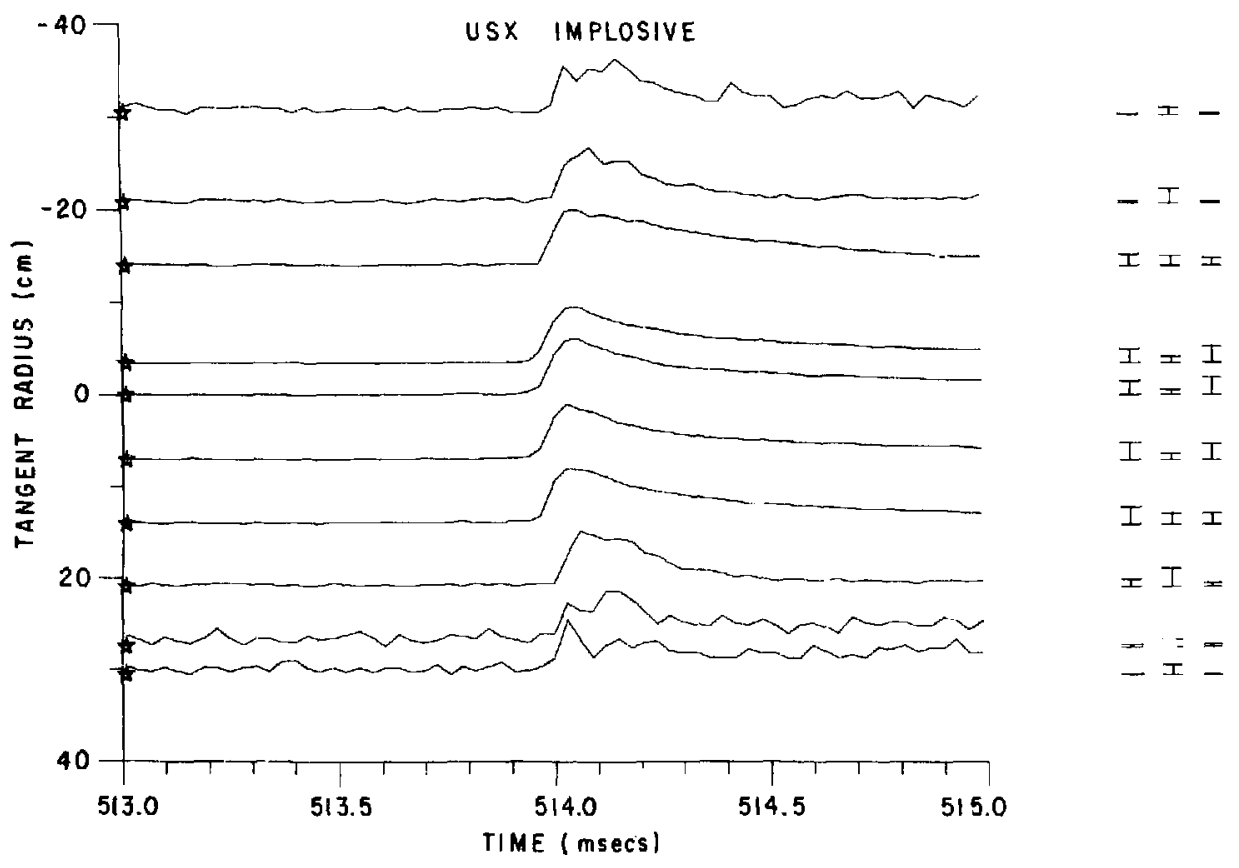

Fig. $1 \mathrm{f}$ 


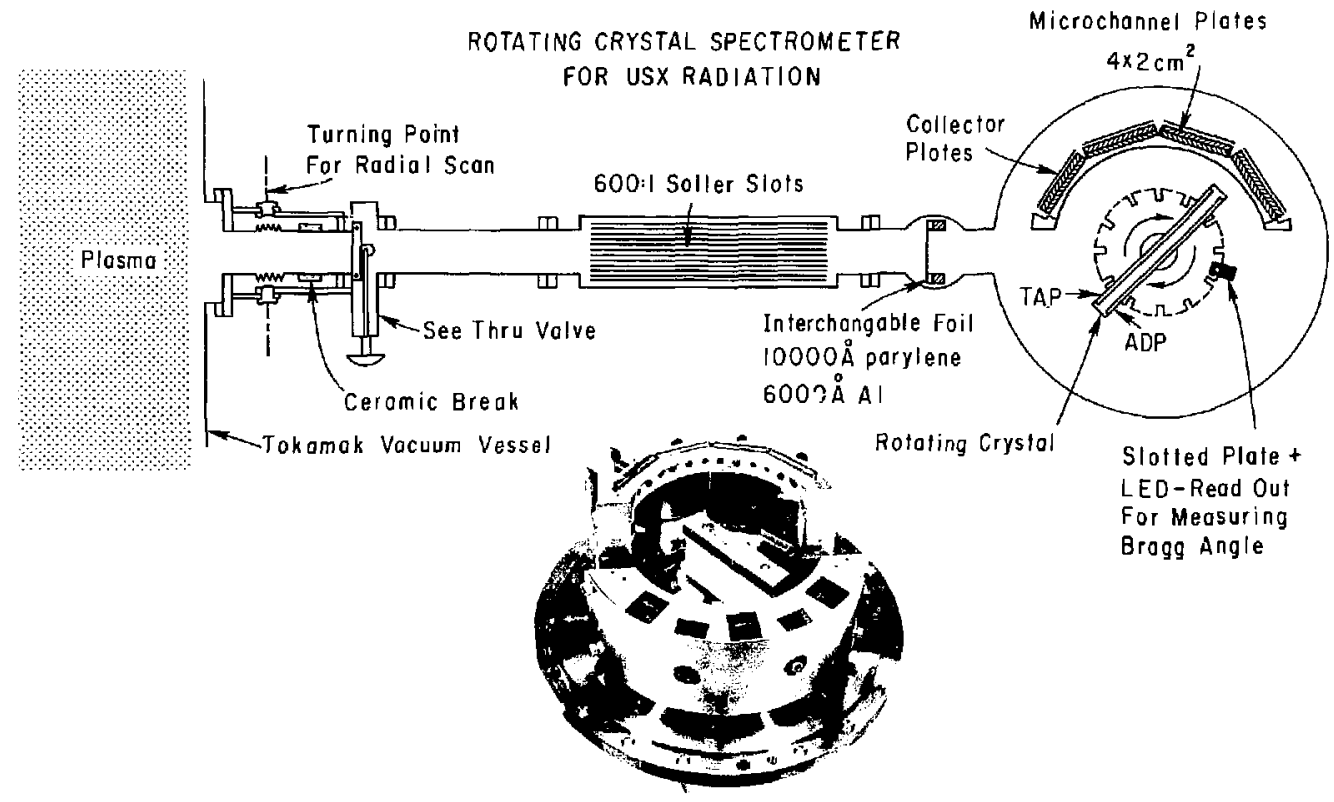

Fig. 17 

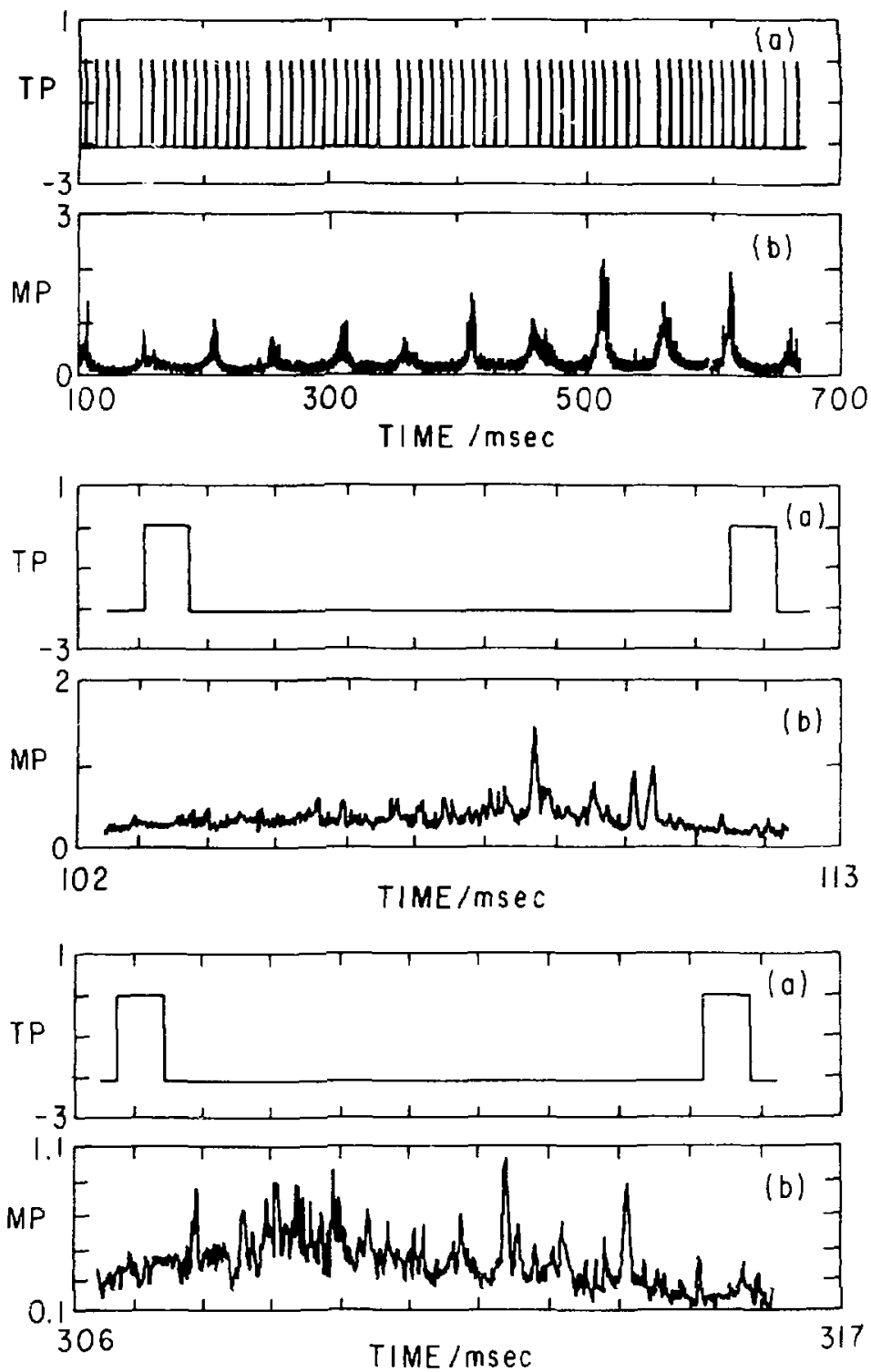


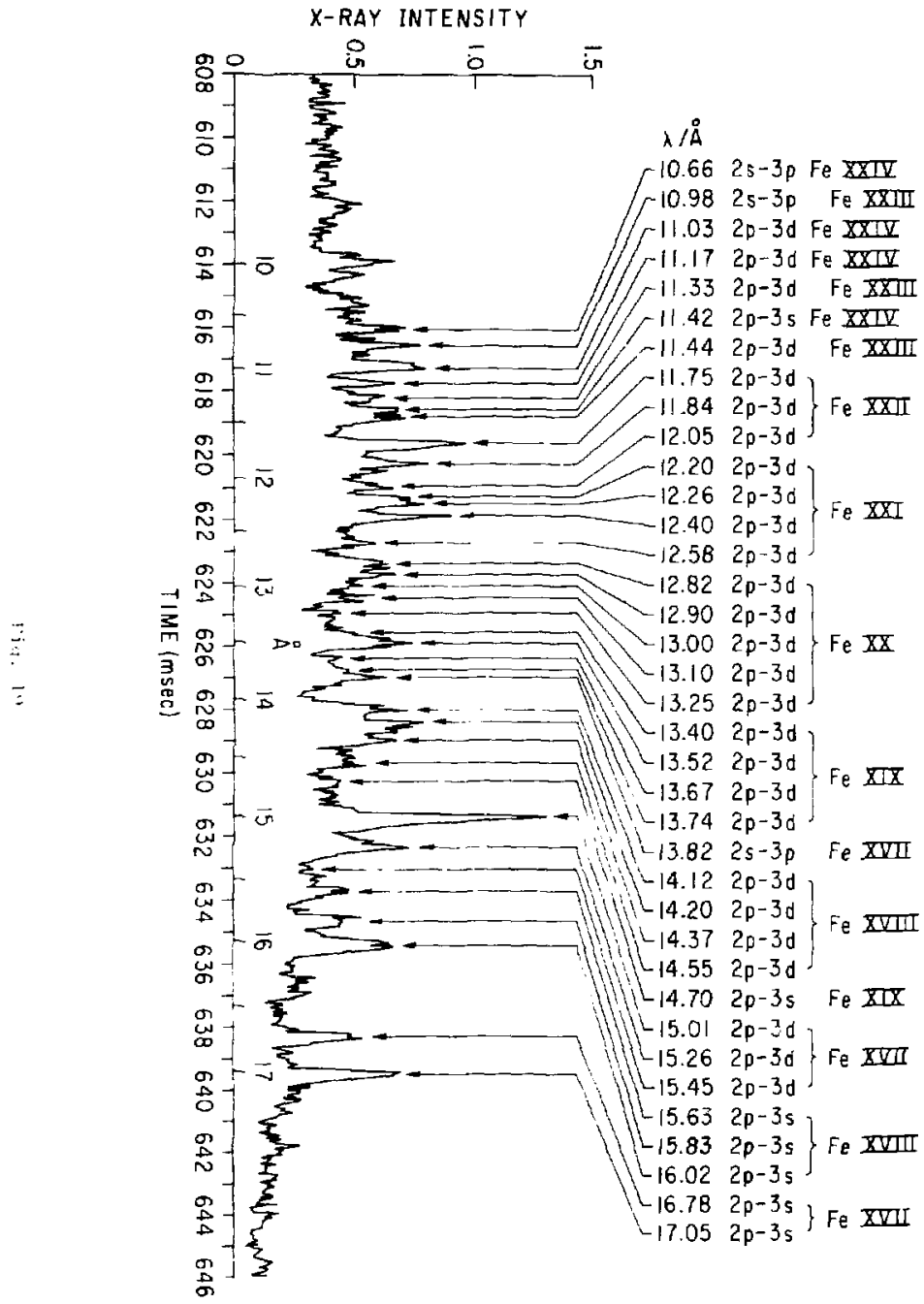




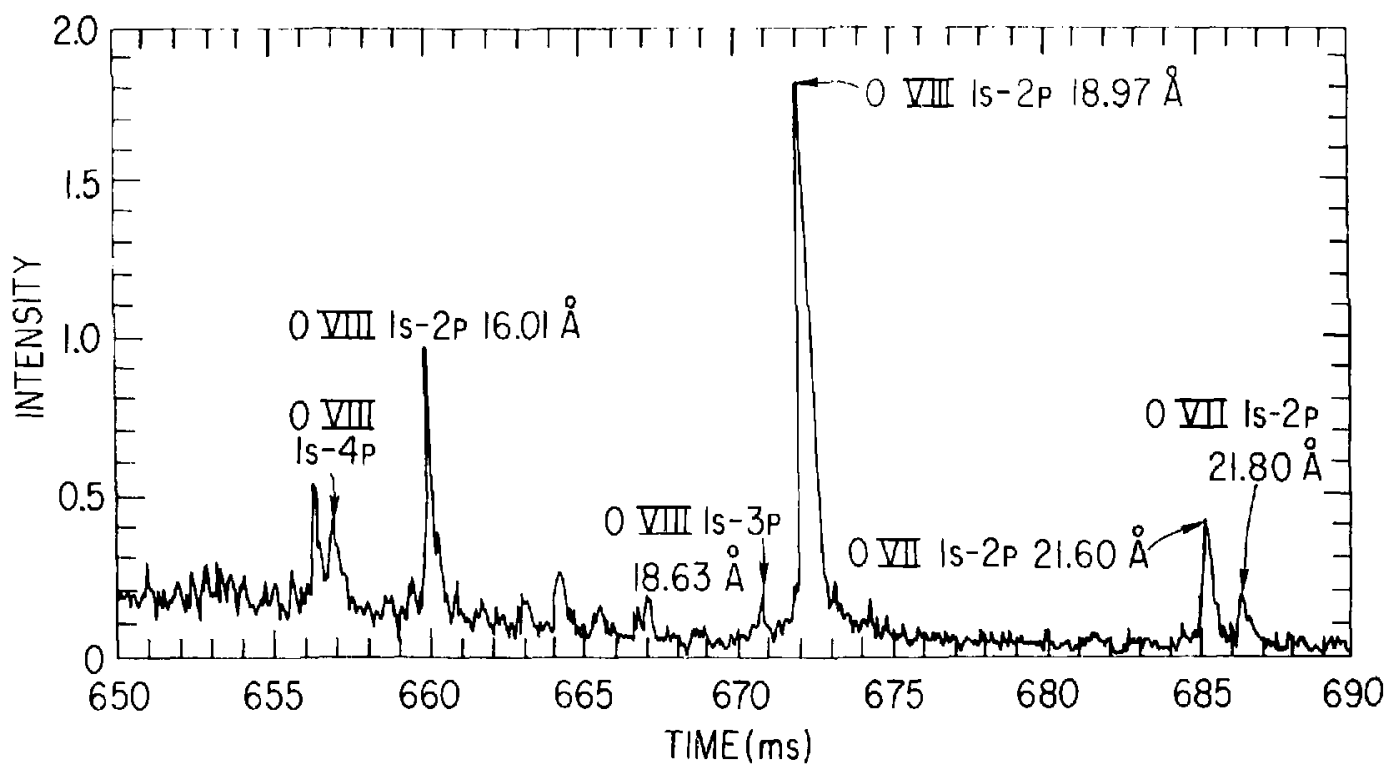




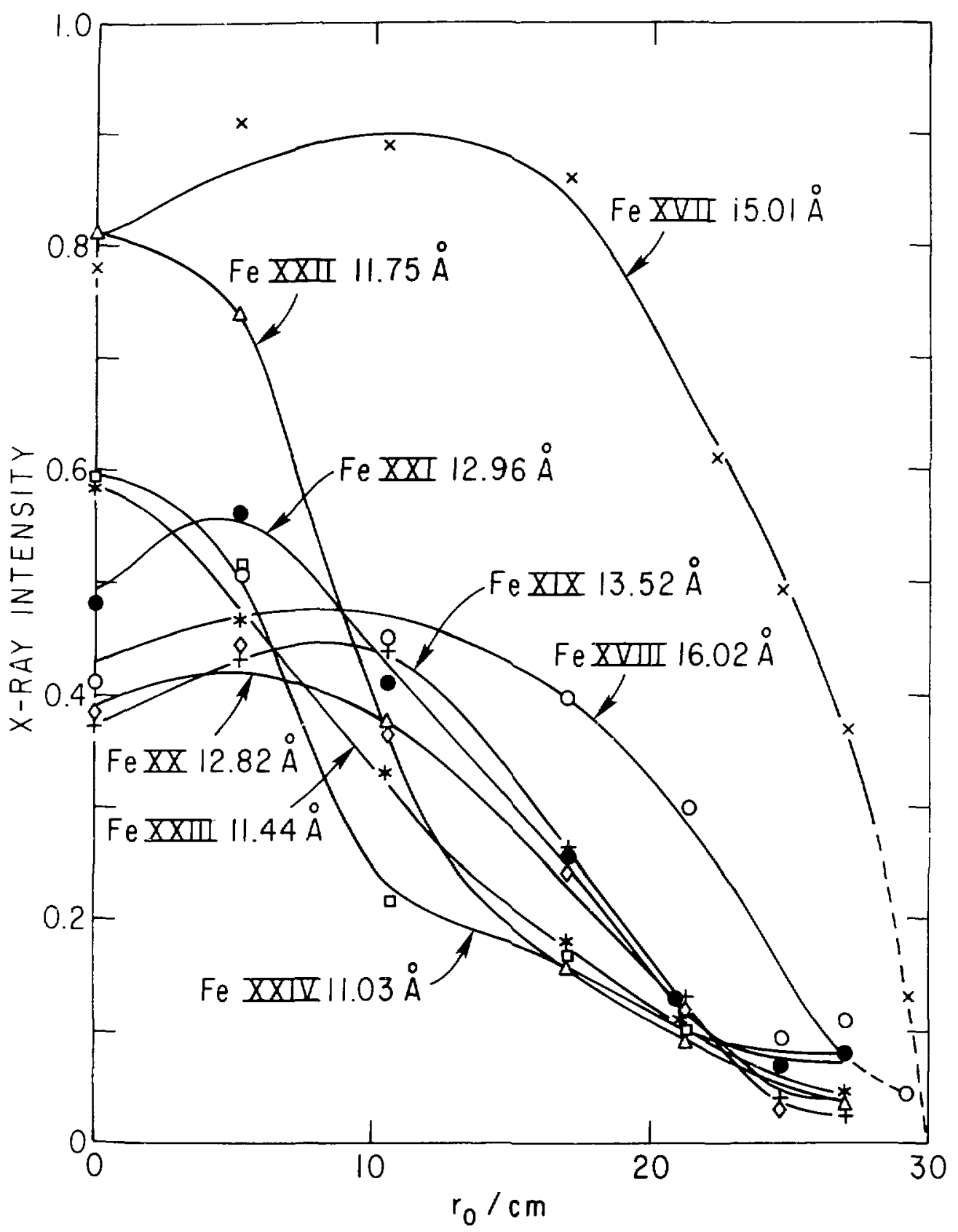

